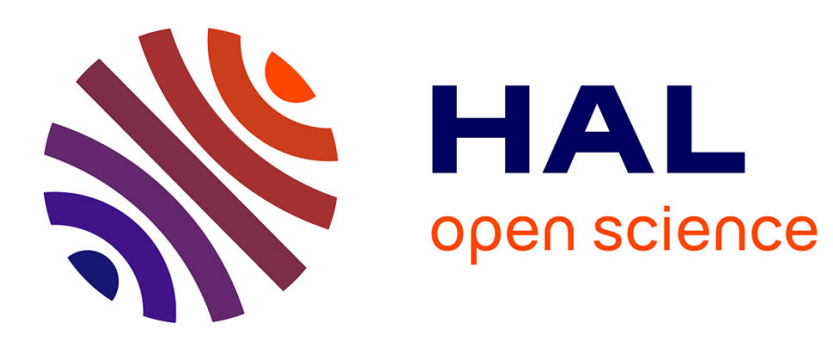

\title{
The distortionary effect of monetary policy: credit expansion vs. lump-sum transfers in the lab \\ Romain Baeriswyl, Camille Cornand
}

\section{To cite this version:}

Romain Baeriswyl, Camille Cornand. The distortionary effect of monetary policy: credit expansion vs. lump-sum transfers in the lab. 2015. halshs-01161854v4

\section{HAL Id: halshs-01161854 \\ https://shs.hal.science/halshs-01161854v4}

Preprint submitted on 13 Nov 2017

HAL is a multi-disciplinary open access archive for the deposit and dissemination of scientific research documents, whether they are published or not. The documents may come from teaching and research institutions in France or abroad, or from public or private research centers.
L'archive ouverte pluridisciplinaire HAL, est destinée au dépôt et à la diffusion de documents scientifiques de niveau recherche, publiés ou non, émanant des établissements d'enseignement et de recherche français ou étrangers, des laboratoires publics ou privés. 


\title{
GATE $_{\text {vossentromex }}$
}

UMR 5824

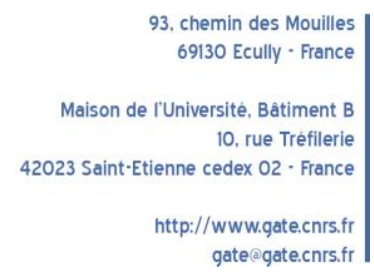

WP 1516 - June 2015, revised September 2017

\section{The distortionary effect of monetary policy: credit expansion vs. lump-sum transfers in the lab}

\author{
Romain Baeriswyl, Camille Cornand
}

\begin{abstract}
:
In an experimental monetary general equilibrium economy, we assess two processes of monetary injection: credit expansion vs. lump-sum monetary transfers. In theory, both processes are neutral and exert no real effect on allocation. In the experiment, however, credit expansion leads to substantial distortions of real allocation and relative prices, and exerts a redistributive effect across subjects. By contrast, an increase in money through lump-sum transfers does not distort real allocation.
\end{abstract}

\section{Keywords:}

laboratory experiment, money neutrality, credit expansion, lump-sum monetary transfers

\section{JEL codes:}

C92, E52, E58

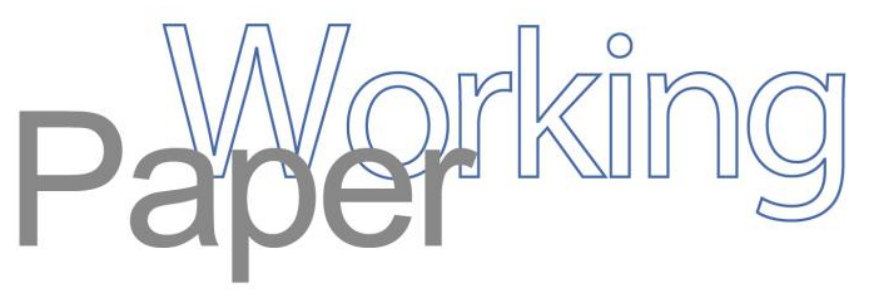




\title{
The distortionary effect of monetary policy: credit expansion vs. lump-sum transfers in the lab*
}

\author{
Romain Baeriswyl $l^{\S}$ \\ Swiss National Bank \\ Camille Cornand $\sharp$ \\ CNRS-GATE
}

September 2017

\begin{abstract}
In an experimental monetary general equilibrium economy, we assess two processes of monetary injection: credit expansion vs. lump-sum monetary transfers. In theory, both processes are neutral and exert no real effect on allocation. In the experiment, however, credit expansion leads to substantial distortions of real allocation and relative prices, and exerts a redistributive effect across subjects. By contrast, an increase in money through lump-sum transfers does not distort real allocation.
\end{abstract}

JEL classification: C92, E52, E58.

Keywords: laboratory experiment, money neutrality, credit expansion, lump-sum monetary transfers.

${ }^{*}$ The views expressed in this paper are those of the authors and do not necessarily reflect those of the Swiss National Bank. We are grateful to Quentin Thévenet for designing the computer software and providing excellent assistance. We are also thankful to the students for their participation in the experiment. Finally, we are grateful to the ANR-DFG joint grant for financial support (ANR-12-FRAL0013-01). This research was performed within the framework of the LABEX CORTEX (ANR-11-LABX0042) of Université de Lyon, within the program "Investissements d'Avenir" (ANR-11-IDEX-007) operated by the French National Research Agency (ANR).

${ }^{\S}$ Swiss National Bank, Boersenstrasse 15, 8022 Zurich, Switzerland; email: romain.baeriswyl@snb.ch

${ }^{\sharp}$ Université de Lyon, Lyon, F-69007, France ; CNRS, GATE Lyon Saint-Etienne, Ecully, F-69130, France; email: cornand@gate.cnrs.fr 


\section{Introduction}

We investigate the allocative effect of monetary policy within an experimental monetary general equilibrium model. The analysis shows that the process by which money is injected into the economy matters for the real allocation of resources. Two processes of monetary injection are under scrutiny: credit expansion and lump-sum transfers. Under credit expansion, money is injected into the credit market as it is created through the granting of credit. By contrast, lump-sum transfers increase the quantity of money in circulation independently of the course of the credit market. In the experiment, credit expansion yields substantially larger distortions than lump-sum transfers.

Motivation The outbreak of the financial crisis in 2007 has rekindled the debate on the effect of fractional reserve banking on the real economy. In the fractional reserve banking system, money is issued through the granting of credit by commercial banks. ${ }^{1}$ Increasing the quantity of money in circulation goes hand in hand with increasing the quantity of credit. While the economic effect of credit expansion has been the object of controversies throughout the ages ${ }^{2}$ recent literature has highlighted severe consequences of credit expansion as reflected by resource misallocation, financial crises and boom-bust cycles. Empirically, the works by Borio and Lowe (2002), Schularick and Taylor (2012), and Baron and Xiong (2017) document the evidence that credit expansions can have disruptive effects on the real economy. Theoretically, the recent work by Krainer (2017) maintains that fractional reserve banking yields a misallocation of resources through excessive risk taking. This raises the question of the unintended consequences of the conduct of monetary policy in that system since the growth in the quantity of money necessary to pursuit price stability may trigger a disruptive credit expansion.

Acknowledging that the intertwined relationship between money and credit can be a source of troubles, the idea has emerged to put money into circulation independently of the credit market through lump-sum transfers. As Friedman (1960, p. 43) put it: "In modern financial systems, the creation of money is linked with lending and investing activity and changes in the stock of money generally take place through the credit markets. There is, however, no necessary connection." Indeed, lump-sum transfers allow the quantity of money to increase independently of the course of the credit market. For instance, Turner (2015) calls for injecting money through lump-sum transfers to mitigate the disruptive effect that monetary policy may exert through credit expansion.

Theoretical hypotheses There are two views on the allocative effect and neutrality of money. On the one hand, standard macroeconomics states that the process of monetary injection is irrelevant because money is, in itself, neutral. Real effects of monetary policy are thus accounted for by means of exogenous frictions in price setting or in information

\footnotetext{
${ }^{1}$ See McLeay et al. (2014) for an exposition of the process of money creation in the current monetary system.

${ }^{2}$ This was the object of the intense debate between the Banking School and the Currency School in the 19th century Great Britain.
} 
gathering. ${ }^{3}$ The process by which money is injected into the economy is unimportant because it does not affect the way exogenous frictions create real effects in the wake of changes in the quantity of money.

On the other hand, a long tradition of economic thought since Cantillon (1755) has highlighted that monetary injections per se are never neutral because money has the greatest effect on the demand for and the price of the goods on which it is first spent. When money enters the economy at a certain point, an increase in the quantity of money primarily affects relative prices rather than all prices to the same extent. As money spreads into the economy, step by step, other markets are also affected by monetary expansion. ${ }^{4}$ Money non-neutrality results from the process of monetary injection itself, rather than from exogenous frictions. In this perspective, the process of monetary injection matters for the allocative effect of monetary policy because it determines where money enters the economy and which markets benefit from the increase in money in the first place. If money enters the credit market at inception, it will stimulate that market more than other markets.

Contributions We explore the allocative effect of monetary injection within a production economy. We develop a theoretical model without frictions, where money is neutral and the process of monetary injection irrelevant. We then bring this theoretical set-up into the lab. The experiment is conducted in such a way to mimic, as closely as possible, the theoretical framework. The lab shows that the allocation of resources differs with the process of monetary injection.

The contribution of this paper is twofold. First, it develops a theoretical model where every exchange is settled with money. The allocation of real resources results from the spending of money on the different markets. Optimal allocation is however independent of the process of monetary injection. Credit expansion and lump-sum transfers are theoretically equivalent in terms of resource allocation. Second, our paper is the first to run a laboratory experiment of a monetary economy with a credit market, where credit expansion is understood as an increase in the quantity of money through the granting of credit. Since a counterfactual analysis of the current credit expansion process cannot be conducted in the field, resorting to a laboratory experiment is appealing. The laboratory allows for designing a controlled environment, in which treatments are perfectly comparable.

The economy In our theoretical and experimental economy, subjects are endowed with input and money, produce two goods with good-specific technology, and derive utility

\footnotetext{
${ }^{3}$ Frictions in price setting have been developed by e.g. Rotemberg (1982) or Calvo (1983), while frictions in information gathering go back to Phelps (1970), Lucas (1972) or, more recently, Mankiw and Reis (2002).

${ }^{4}$ Whereas Cantillon (1755) described the intersectoral effect of changes in the quantity of money, other authors such as Mises (1912) and Hayek (1928) have stressed the fact that the injection of money into the credit market exerts an intertemporal discoordination as it lowers interest rate below its natural level and yields a discrepancy between investment and voluntary savings. Ledoit (2011) accounts in a formal model for the redistributive effect of monetary policy.
} 
from consuming these two goods. Subjects are homogenous with respect to endowment of input and money and to production technology, but have different utility preferences. Money does not provide utility in itself but serves as a means of exchange to settle all transactions. Our analysis focuses on the role of money prices for economic calculation and for the allocation of resources. Money prices reflect the relative productivity of technology and the relative preference for consumption of goods, and coordinate the input allocation into the production of goods such that it maximises utility derived from consumption.

The specificity of our model consists in that the allocation of resources results from the spending of money on the different markets. Money, thus, does not simply fulfill a trivial role in the model - as it is the case with money-in-the-utility or cash-in-advance assumptions - but truly commands the allocation of economic goods.

Endowed with input and money, subjects have three decisions to make. First, each subject decides how to split his money endowment between investing in the production of good 1 and lending on the credit market, second, how much to borrow from the credit market to invest in the production of good 2, and third, how to spend his production earnings between the consumption of goods 1 and 2 .

Money can enter the economy either through lump-sum transfers to the subjects or through credit expansion. Lump-sum transfers are performed by an increase in the money endowment of each subject. By contrast, credit expansion are performed by an increase in the money offered on the credit market. Theory says that the process of monetary injection has no effect on the optimal allocation of resources. It however predicts subjects to adjust their behaviour to the process of monetary injection in such a way that allocation remains optimal: whereas an increase in money through lump-sum transfers calls for a proportional increase in lending and borrowing, an increase in money through credit expansion calls for a reduction in lending but for an increase in borrowing, such that aggregated real lending remains unaffected.

The experiment The experiment is run with three treatments, each corresponding to a process of monetary injection. In the baseline treatment, subjects are endowed with a certain quantity of money and there is no credit expansion. In the credit expansion treatment, subjects' money endowment remains the same as in the baseline, but there is an additional quantity of money offered into the credit market. In the lump-sum transfers treatment, there is no credit expansion but the subjects' money endowment is larger than in the baseline such that the overall quantity of money is the same as in the credit expansion treatment. In the baseline and the lump-sum transfers treatments, the supply of credit consists of the part of money endowment lent by subjects on the market. In the credit expansion treatment, the supply of credit includes, in addition to the money lent by subjects, the new money created through the granting of credit.

Results Although the theoretical model brought into the lab predicts, in line with frictionless mainstream economics, the neutrality of money, the laboratory experiment sup- 
ports the Cantillon insight that the process of monetary injection shapes the allocation of resources. The experiment shows that subjects find it more challenging to reach equilibrium under credit expansion, leading to substantial deviations from optimal allocation. Credit expansion entails distortions in the production allocation that are substantially larger than with lump-sum transfers. This can be explained by the stimulating effect that credit expansion exerts on the credit market and on the production of good 2 in the first place, whereas lump-sum transfers affect the production of goods 1 and 2 evenly. These deviations also exert a redistributive effect across subjects in favor of those who have a high consumption preference for good 2, whose production is stimulated by credit expansion.

Related literature The present paper relates to the experimental literature on money and credit. To the best of our knowledge, our paper is the first to test in the lab credit expansion, understood as an injection of money into the credit market.

Experiments on money have highlighted money illusion in the laboratory (Fehr and Tyran (2001) and Fehr and Tyran (2008)) or have shown that monetary trade emerges in search-models (Duffy and Ochs (1999) and Duffy and Puzzello (2014)) and improves impersonal exchanges in a decentralised economy (Camera and Casari (2014)). A growing literature has also performed experiments on New Keynesian DSGE models, in which subjects play the roles of consumers, workers, producers, and possibly central bankers. ${ }^{5}$ These experiments, however, do not implement monetary exchanges.

Lian and Plott (1998) is probably the paper the most closely related to ours. They experiment a general equilibrium framework with monetary exchanges for exploring the technical feasibility of running complex experiments in the laboratory. The proximity lies in the methodological feasibility of running an experimental monetary economy and in the study of the impact of a monetary injection. They however exclusively analyse lump-sum transfers and find that money supply has some impact on nominal variables but not on real variables, a result confirmed in our experiment. Although an access to a bond market is granted for the case where cash-in-advance constraints bind, their credit market plays only a subordinate role and is often not used because of complexity. By contrast, in our framework, lending and borrowing play a central role in production allocation and for monetary injection in the credit expansion treatment.

Experiments on credit include Bosch-Domenech and Silvestre (1997), who have investigated the effect of credit tightness in a barter economy. Because there is no money, they model the credit market as pure financial intermediation where lenders and borrowers exchange present goods against future goods. Subjects' ability to enter into credit transaction is limited by an exogenous credit bound determined by the share of future revenue that can be exchanged against present consumption. They analyse the effect of changes in the credit bound on activity and relative prices. Although they call an increase in the

\footnotetext{
${ }^{5}$ For example, Noussair et al. (2014) or Kryvtsov and Petersen (2013) study the role of frictions (menu costs, monopolistic competition) for replicating stylised facts and the persistence of shocks. They show that monopolistic competition in the output market is sufficient to generate persistent effects of shocks, while menu costs are not necessary. Petersen (2015) also uses a DSGE experiment for studying how households and firms respond to monetary shocks.
} 
credit bound a credit expansion, it is important to note that it describes a very different economic phenomenon from credit expansion captured in our experiment. In their experiment, credit expansion means a relaxation of an exogenous (suboptimal) limit to credit transactions, while, in our framework, it means an increase in credit supply through the creation of the money lent.

The structure of the paper is as follows. In section 2, the theoretical model is presented and the equilibrium derived. The experimental setup is discussed in section 3, while section 4 gives the results of the experiment and describes the behaviour of participants. Section 5 concludes.

\section{The economy}

This section specifies a monetary general equilibrium economy where agents produce and consume two goods, good 1 and good 2. The economy is populated by $n$ agents. Each agent is endowed with a quantity of input and with a quantity of money. We derive first the optimal allocation of resources in absence of money to emphasise the properties of the real economy. We introduce money in a second step and determine the optimal monetary decisions of agents when every transaction is settled with money.

\subsection{The real economy}

\subsubsection{Endowment, production technology and utility function}

Each agent $i$ is endowed with the same quantity of real input $L_{i}$. Input is used in the production of two goods. $L_{i, 1}$ is the input devoted by agent $i$ to the production of good $1, g_{i, 1}$, and $L_{i, 2}$ the input devoted to the production of good $2, g_{i, 2}$. The production technologies are given by

$$
\begin{aligned}
& g_{i, 1}=L_{i, 1} \\
& g_{i, 2}=L_{i, 2}^{\beta} \quad \text { with } 0<\beta<1
\end{aligned}
$$

Input devoted by agent $i$ to production of both goods, $L_{i, 1}+L_{i, 2}$, must not necessarily equal his initial endowment $L_{i}$ because - as we shall see below - agents sell their endowed input and purchase their invested input on the market. However, in aggregate, the sum of input devoted to production over all agents, $\sum_{i}\left(L_{i, 1}+L_{i, 2}\right)$, is equal to the sum of input endowment, $\sum_{i} L_{i}=L$.

Agent $i$ derives utility from the consumption of good $1, c_{i, 1}$, and good $2, c_{i, 2}$. Utility is given by the Cobb-Douglas function

$$
U_{i}=c_{i, 1}^{\alpha_{i}} \cdot c_{i, 2}^{1-\alpha_{i}}
$$

with $0<\alpha_{i}<1$. The production of good 1 by agent $i, g_{i, 1}$, must not necessarily equal its consumption $c_{i, 1}$ because agents sell their production and purchase their consumption on 
the market. However, the overall production of good 1 equals the overall consumption of good 1: $\sum_{i} g_{i, 1}=g_{1}=\sum_{i} c_{i, 1}=c_{1}$. The same is true for good 2 .

\subsubsection{The optimal real allocation with market exchanges}

The optimal allocation of real resources can be separated into two parts. First, each agent optimises his production decision to maximise his budget. Second, each agent optimises his consumption decision subject to his budget restriction. Optimal consumption is dependent on the agent specific parameter $\alpha_{i}$ in (1).

Production decision Agent $i$ chooses his production of good 1 and good 2 to maximise his budget subject to his input. The optimisation problem is solved with the Lagrangian

$$
\begin{aligned}
\mathcal{L} & =g_{i, 1} \cdot p_{1}+g_{i, 2} \cdot p_{2}+\lambda\left[L_{i}-g_{i, 1}-g_{i, 2}^{1 / \beta}\right] \\
\frac{\partial \mathcal{L}}{\partial g_{i, 1}} & =p_{1}-\lambda=0 \\
\frac{\partial \mathcal{L}}{\partial g_{i, 2}} & =p_{2}-\lambda \cdot \frac{1}{\beta} \cdot g_{i, 2}^{(1-\beta) / \beta}=0
\end{aligned}
$$

Combining these first-order conditions yields the optimal relative price

$$
\frac{p_{1}}{p_{2}}=\beta \cdot g_{i, 2}^{(\beta-1) / \beta}
$$

Consumption decision Agent $i$ allocates his budget $B_{i}$ between good 1 and good 2 to maximise his utility (1), taking the prices $p_{1}$ and $p_{2}$ as given. The optimisation problem is solved with the Lagrangian

$$
\begin{aligned}
\mathcal{L} & =c_{i, 1}^{\alpha_{i}} \cdot c_{i, 2}^{1-\alpha_{i}}+\lambda\left[B_{i}-c_{i, 1} p_{1}-c_{i, 2} p_{2}\right] \\
\frac{\partial \mathcal{L}}{\partial c_{i, 1}} & =\alpha_{i} \cdot c_{i, 1}^{\alpha_{i}-1} \cdot c_{i, 2}^{1-\alpha_{i}}-\lambda p_{1}=0 \\
\frac{\partial \mathcal{L}}{\partial c_{i, 2}} & =\left(1-\alpha_{i}\right) \cdot c_{i, 1}^{\alpha_{i}} \cdot c_{i, 2}^{-\alpha_{i}}-\lambda p_{2}=0
\end{aligned}
$$

and the optimal consumption condition is given by

$$
\frac{c_{i, 1}}{c_{i, 2}}=\frac{\alpha_{i}}{1-\alpha_{i}} \frac{p_{2}}{p_{1}} \quad \Leftrightarrow \quad c_{i, 1} p_{1}=\alpha_{i} B_{i}
$$

The optimal consumption spending on good 1 corresponds to the proportion $\alpha_{i}$ of agent's budget. Using the fact that each agent commands the same budget in equilibrium and aggregating optimal consumption over all agents, the relative price between good 1 and 
good 2 can be expressed as:

$$
\begin{aligned}
\sum_{i} c_{i, 1} \cdot p_{1} & =\sum_{i} \alpha_{i}\left(c_{i, 1} \cdot p_{1}+c_{i, 2} \cdot p_{2}\right) \\
c_{1} \cdot p_{1} & =\bar{\alpha}\left(c_{1} \cdot p_{1}+c_{2} \cdot p_{2}\right) \\
\frac{p_{1}}{p_{2}} & =\frac{\bar{\alpha}}{1-\bar{\alpha}} \frac{c_{2}}{c_{1}}
\end{aligned}
$$

where $\bar{\alpha}$ stands for the average parameter $\alpha_{i}$ across agents. The relative price is the inverse of the relative quantity of goods (produced as well as consumed) times their relative average preference in utility.

Equilibrium Combining (2) and (4), and noting that $\frac{c_{2}}{c_{1}}=\frac{g_{i, 2}}{g_{i, 1}}$ since optimal production is identical for every agent, equilibrium production is given by

$$
\begin{aligned}
g_{i, 1} & =L_{i, 1}=\frac{\bar{\alpha}}{\bar{\alpha}+\beta(1-\bar{\alpha})} L_{i} \\
g_{i, 2} & =L_{i, 2}^{\beta}=\left(\frac{\beta(1-\bar{\alpha})}{\bar{\alpha}+\beta(1-\bar{\alpha})} L_{i}\right)^{\beta}
\end{aligned}
$$

\subsection{The monetary economy}

After having derived the optimal real allocation of the economy, we introduce now its monetary counterpart. Like in reality, money plays in our model the role of medium of exchange as every transaction is settled with money. The real allocation of resources is driven by the quantity of money spent on each particular market. Money also plays the role of unit of account as it allows agents to perform economic calculations in terms of money prices. The money prices determined in the market synthetise the various preferences and technologies available, and coordinate agents' action.

The relationship between the monetary and the real economy is illustrated in Figure 1. Monetary components are drawn in orange and real components in blue.

\subsubsection{Some assumptions}

The economy is stylised and has the following characteristics:

- An agent cannot make own use of his input, money lent and produced goods. He must sell his input endowment and buy input for production at the market price, lend and borrow at the market interest rate, sell and buy produced goods at the market price to earn his income and to consume. The assumption of 'no own use' is a useful trick to give a role to market exchanges when agents are homogenous (with respect to endowment and to production technology). ${ }^{6}$

\footnotetext{
${ }^{6}$ Another, perhaps more intuitive, way to give a role to market exchanges would be to split subjects between lenders and borrowers, and between producers and consumers. This would however require a much larger number of subjects in every experimental session, without adding any benefit compared to our setup which means that each subject takes part in both sides of every market.
} 


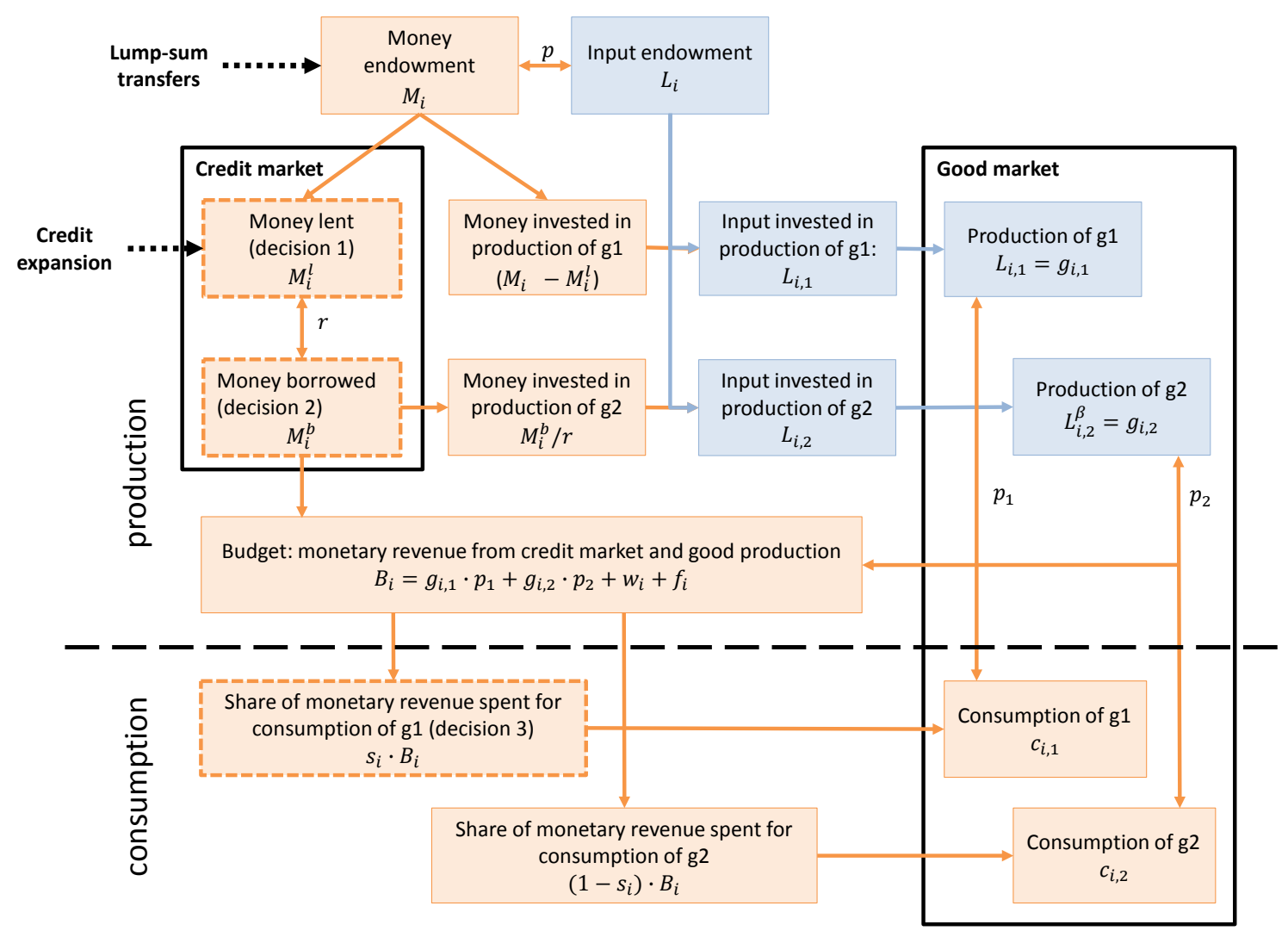

Figure 1: Scheme of the monetary economy

- An agent must borrow on the credit market the money he invests in the production of good 2. This restriction is essential in our model to capture the fact that some economic sectors (like the real estate sector) are particularly dependent on credit, and that the credit market does not affect all economic sectors evenly.

- An agent cannot hoard money but decides how to allocate his money between the production of good 1 and the production of good 2, on the one hand, and how to spend his money earned between the consumption of good 1 and the consumption of good 2, on the other. In decision one, each agent decides how much money he lends on the credit market, while the residuum of money endowment is spent on the purchase of input for the production of good 1. In decision two, each agent decides how much money he borrows on the credit market to purchase input for the production of good 2. In decision three, each agent decides how to spend his entire revenue for the consumption of good 1 and good 2 .

- Market prices are simultaneously determined on all markets such that markets clear. Rather than relying on double auctions, as it is often the case in experiments, prices are determined to satisfy the law of one price on each market. The double auction bidding system may be useful to illustrate how the market processes decentralised information into prices. It is, however, not appropriate in our setup where each 
agent sells and buys on the market as it would allow each agent to deal with himself at a price different from the market price. The simultaneous determination of all prices ensures that all transactions occur at the market clearing price.

\subsubsection{Monetary decisions of agents}

In addition of being endowed with input $L_{i}$ as exposed in section 2.1.1, each agent is endowed with the quantity of money $M_{i}$ and makes three monetary decisions that determine his production and consumption.

1. Lending decision - allocation of input between production of good 1 and good 2: each agent $i$ decides how much of his money endowment $M_{i}$ he lends on the credit market $M_{i}^{l}$, with $0 \leq M_{i}^{l} \leq M_{i}$. Money lent earns an interest rate $r$. The residual, $M_{i}-M_{i}^{l}$, is the money spent for the purchase of input assigned to the production of good 1. At the individual level, the lending decision determines the production of good 1 of each agent. At the aggregate level, the lending decision determines the allocation of input between the production of good 1 and good 2, because the quantity of money lent determines how much money will effectively be borrowed for the production of good 2 .

2. Borrowing decision - allocation across agents of input for the production of good 2: each agent $i$ decides how much money he borrows on the credit market, $0 \leq M_{i}^{b}$. Borrowing money costs an interest rate $r$. Money borrowed is spent for purchasing input assigned to the production of good 2 . The money borrowed by each agent must not correspond to his money lent. However, interest rate $r$ clears the market such that the aggregate money borrowed $\sum_{i} M_{i}^{b}$ equals the aggregate money lent $\sum_{i} M_{i}^{l}$. While the aggregate input assigned to the production of good 2 is determined by the lending decision 1 , the borrowing decision 2 determines the allocation across agents of production of good 2 .

3. Consumption decision: each agent $i$ decides the proportion $s_{i}$, with $0 \leq s_{i} \leq 1$, of his monetary earnings to spend on the consumption of good 1 . The residual proportion, $1-s_{i}$, is spent on the consumption of good 2. Monetary earnings (budget) are composed of the revenue of selling production on the good market, of the net revenue from lending and borrowing on the credit market, and of the net revenue from the input market.

\subsubsection{Monetary policy}

Two monetary systems are considered. In the first monetary system, the increase in the quantity of money takes place through an increase in the supply of credit. Credit expansion reflects the functioning of the current credit-money economy, where money is created through the granting of credit. Money injected into the credit market is denoted $K$ and the overall quantity of money in the economy is $M+K$, with $M=\sum_{i} M_{i}$. The 
total amount of money lent in the credit market corresponds to the money lent by agents $\sum_{i} M_{i}^{l}$ plus the new money offered as credit supply $K$. For convenience, the quantity of money per agent injected into the credit market is written $\bar{K}_{i}=K / n$.

In the second monetary system, the increase in the quantity of money occurs through lump-sum monetary transfers to agents. An increase in money is implemented by simply changing the quantity of money endowment of each agent, $M_{i}$. In this case, the increase in money does not directly influence the credit market $(K=0)$. The overall quantity of money in the economy is $M$.

\subsubsection{Market clearing}

Prices are determined to clear all markets. The economy consists of four prices: $p$ is the price of input, $r$ is the interest rate for the money lent and borrowed, $p_{1}$ is the price of good 1 , and $p_{2}$ is the price of good 2 .

Input price The entire quantity of money $M+K$ is spent for the purchase of input $L$. The market clearing money price of one unit of input is

$$
p=(M+K) / L
$$

The net revenue of agent $i$ from the input market is $w_{i}=p \cdot\left(L_{i}-L_{i, 1}-L_{i, 2}\right)$, with $\sum_{i} w_{i}=0$. The money lent by agent $i$ on the credit market in decision $1, M_{i}^{l}$, determines the input quantity purchased by agent $i$ for the production of good $1:\left(M_{i}-M_{i}^{l}\right) / p=L_{i, 1}$. Input purchased for the production of good 2 is determined by the borrowing decision 2 : $M_{i}^{b} /(r p)=L_{i, 2}$.

Interest rate Agents lend and borrow money on the credit market. The aggregated supply of lending consists of the money lent by agents, $M^{l}=\sum_{i} M_{i}^{l}$, plus the money injected into the credit market in the credit expansion system, $K$. The aggregated demand for borrowing is $M^{b}=\sum_{i} M_{i}^{b}$. The market clearing interest rate is determined as

$$
r=\frac{M^{b}}{M^{l}+K}
$$

Agent $i$ decides upon his supply of lending $M_{i}^{l}$ and his demand for borrowing $M_{i}^{b}$. Since in aggregate the money borrowed equals the money lent, the money effectively borrowed by agent $i$ is a fraction of his demand for borrowing, $M_{i}^{b} / r$, and the repayment of capital and interest is $M_{i}^{b}$. This implies that the overall allocation of input between the production of good 1 and good 2 is determined by lending decisions, while borrowing decisions merely determine the allocation across agents of the production of good 2. The aggregate input assigned to the production of good 1 is given by $\sum_{i}\left(M_{i}-M_{i}^{l}\right) / p=L_{1}$. The aggregate input assigned to the production of good 2 is given by $\sum_{i} M_{i}^{l} / r p=L_{2}$.

The interest rate revenue from the money injected into the credit market $(r-1) \cdot K$ 
(i.e. seigniorage) is evenly split across all agents. The net revenue of agent $i$ from the credit market is $f_{i}=(r-1) \cdot\left(M_{i}^{l}-M_{i}^{b} / r+K / n\right)$, with $\sum_{i} f_{i}=0$.

Price of good 1 and good 2 The budget of agent $i$ available for consumption is made of the revenue of selling production $g_{i, 1}$ and $g_{i, 2}$ at their market price $p_{1}$ and $p_{2}$, of the revenue of the input market $w_{i}$, and of the revenue of the credit market $f_{i}$ :

$$
B_{i}=g_{i, 1} \cdot p_{1}+g_{i, 2} \cdot p_{2}+w_{i}+f_{i}
$$

The determination of the money prices of good 1 and good $2, p_{1}$ and $p_{2}$, is driven by the way agents spend their revenue on the consumption of good 1 and good $2, s_{i}$. It must satisfy:

$$
\begin{aligned}
& \sum_{i} g_{i, 1} \cdot p_{1}=\sum_{i} s_{i}\left(g_{i, 1} \cdot p_{1}+g_{i, 2} \cdot p_{2}+w_{i}+f_{i}\right) \\
& \sum_{i} g_{i, 2} \cdot p_{2}=\sum_{i}\left(1-s_{i}\right)\left(g_{i, 1} \cdot p_{1}+g_{i, 2} \cdot p_{2}+w_{i}+f_{i}\right)
\end{aligned}
$$

Using $\sum_{i} B_{i}=\sum_{i} g_{i, 1} p_{1}+\sum_{i} g_{i, 2} p_{2},(7)$ can be rewritten

$$
\sum_{i}\left(1-s_{i}\right) g_{i, 1} \cdot \frac{\sum_{i} B_{i}-\sum_{i} g_{i, 2} \cdot p_{2}}{\sum_{i} g_{i, 1}}=\sum_{i} s_{i}\left(g_{i, 2} \cdot p_{2}+w_{i}+f_{i}\right)
$$

and the market clearing prices are

$$
\begin{aligned}
& p_{1}=\frac{\sum_{i} s_{i} g_{i, 2} B-\sum_{i}\left(1-s_{i}\right)\left(w_{i}+f_{i}\right) g_{2}}{\sum_{i}\left(1-s_{i}\right) g_{i, 1} g_{2}+\sum_{i} s_{i} g_{i, 2} g_{1}} \\
& p_{2}=\frac{\sum_{i}\left(1-s_{i}\right) g_{i, 1} B-\sum_{i} s_{i}\left(w_{i}+f_{i}\right) g_{1}}{\sum_{i}\left(1-s_{i}\right) g_{i, 1} g_{2}+\sum_{i} s_{i} g_{i, 2} g_{1}}
\end{aligned}
$$

with $B=\sum_{i} B_{i}=M+K, g_{1}=\sum_{i} g_{i, 1}$, and $g_{2}=\sum_{i} g_{i, 2}$.

\subsubsection{First-order conditions}

As in the real economy, the optimal behaviour of agents can be separated into two parts. First, each agent optimises his lending and borrowing decisions to maximise his budget. Second, given his budget, each agent optimises his consumption spending between good 1 and good 2 to maximise his utility. 
Lending and borrowing decisions Agent $i$ maximises his budget by making lending and borrowing decisions. Maximising the budget

$$
\begin{aligned}
B_{i}= & \underbrace{\frac{M_{i}-M_{i}^{l}}{p}}_{g_{i, 1}} p_{1}+\underbrace{\left(\frac{M_{i}^{b}}{r p}\right)^{\beta}}_{g_{i, 2}} p_{2}+\underbrace{p\left(L_{i}-\frac{M_{i}-M_{i}^{l}}{p}-\frac{M_{i}^{b}}{r p}\right)}_{w_{i}} \\
& +\underbrace{(r-1)\left(M_{i}^{l}-\frac{M_{i}^{b}}{r}+\frac{K}{n}\right)}_{f_{i}} \\
= & \frac{M_{i}-M_{i}^{l}}{p} p_{1}+\left(\frac{M_{i}^{b}}{r p}\right)^{\beta} p_{2}+r M_{i}^{l}-M_{i}^{b}+r \frac{K}{n}
\end{aligned}
$$

with respect to $M_{i}^{l}$ and $M_{i}^{b}$ yields

$$
\begin{aligned}
& \frac{\partial B_{i}}{\partial M_{i}^{l}}=0 \quad \Leftrightarrow \quad p_{1}=r p \\
& \frac{\partial B_{i}}{\partial M_{i}^{b}}=0 \quad \Leftrightarrow \quad \beta p_{2}\left(\frac{M_{i}^{b}}{r p}\right)^{\beta-1}=r p
\end{aligned}
$$

Condition for optimal lending (9) says that it is optimal to increase the production of good 1 (i.e. to reduce lending) as long as its price $p_{1}$ exceeds its opportunity production cost $r p$. Condition for optimal borrowing (10) says that it is optimal to increase the production of good 2 (i.e. to increase borrowing) as long as its marginal profit $\beta p_{2}\left(M_{i}^{b} / r p\right)^{\beta-1}$ exceeds its production cost $r p$.

Consumption decision The optimal allocation of the budget of agent $i, B_{i}$, between good 1 and good 2 is the same as in the real economy and is given by (3). The optimal consumption spending on good 1 is the proportion $\alpha_{i}$ of agent's budget. The optimal portion of money to spend on good 1 is $s_{i}=\alpha_{i}$.

\subsubsection{Equilibrium}

Combining the first-order conditions (9) and (10), the relative price of good 1 and good 2 can be expressed as

$$
\frac{p_{1}}{p_{2}}=\beta\left(\frac{M_{i}^{b}}{r p}\right)^{\beta-1}=\beta\left(\frac{\bar{M}_{i}^{l}+\bar{K}_{i}}{p}\right)^{\beta-1}
$$

where $\bar{M}_{i}^{l}$ is the average amount of money lent $\left(\bar{M}_{i}^{l}=\sum_{i} M_{i}^{l} / n=M^{l} / n\right)$. Since the production technology of good 1 is linear, the distribution of the money lent across agents is irrelevant. By contrast, each agent should borrow the same amount of money in equilibrium because the production technology of good 2 has decreasing return with $0<\beta<1$.

Using $\bar{\alpha} B_{i}=p_{1}\left(L_{i}-\frac{\bar{M}_{i}^{l}+\bar{K}_{i}}{p}\right)$ and $(1-\bar{\alpha}) B_{i}=p_{2}\left(\frac{\bar{M}_{i}^{l}+\bar{K}_{i}}{p}\right)^{\beta}$, the relative price can be 
rewritten as

$$
\frac{p_{1}}{p_{2}}=\frac{\bar{\alpha}}{1-\bar{\alpha}} \frac{\left(\frac{\bar{M}_{i}^{l}+\bar{K}_{i}}{p}\right)^{\beta}}{L_{i}-\frac{\bar{M}_{i}^{l}+\bar{K}_{i}}{p}}
$$

Combining (11) and (12), we get the equilibrium (average) supply of lending

$$
\bar{M}_{i}^{l}=\frac{\beta(1-\bar{\alpha})}{\bar{\alpha}+\beta(1-\bar{\alpha})} \bar{M}_{i}-\frac{\bar{\alpha}}{\bar{\alpha}+\beta(1-\bar{\alpha})} \bar{K}_{i}
$$

the equilibrium demand for borrowing

$$
M_{i}^{b}=r\left(\bar{M}_{i}^{l}+\bar{K}_{i}\right)=\beta(1-\bar{\alpha})\left(\bar{M}_{i}+\bar{K}_{i}\right)
$$

the equilibrium price of good 1

$$
p_{1}=(\bar{\alpha}+\beta(1-\bar{\alpha})) \frac{\bar{M}_{i}+\bar{K}_{i}}{L_{i}}
$$

the equilibrium price of good 2

$$
p_{2}=(1-\bar{\alpha})\left(\frac{\beta(1-\bar{\alpha})}{\bar{\alpha}+\beta(1-\bar{\alpha})} \bar{L}_{i}\right)^{-\beta}\left(\bar{M}_{i}+\bar{K}_{i}\right)
$$

the equilibrium interest rate

$$
r=\bar{\alpha}+\beta(1-\bar{\alpha})
$$

the equilibrium total production of good 1

$$
g_{1}=\frac{\bar{\alpha}}{\bar{\alpha}+\beta(1-\bar{\alpha})} L
$$

and the equilibrium individual production of good 2

$$
g_{i, 2}=\left(\frac{\beta(1-\bar{\alpha})}{\bar{\alpha}+\beta(1-\bar{\alpha})} L_{i}\right)^{\beta}
$$

The optimal production in the monetary economy is identical to the optimal allocation (5) and (6) in the real economy. The equilibrium interest rate and production of goods 1 and 2 are independent of the quantity of money and reflects the average consumption preference for good 1 relative to good $2, \bar{\alpha}$, the coefficient of the production technology of good $2, \beta$, and the input endowment, $L$. The monetary economy, however, describes the lending, borrowing and consumption spending that yield the optimal real allocation. 


\subsubsection{Theoretical reaction to monetary policy}

The general equilibrium economy shows that the equilibrium allocation of resources is independent of the quantity of money. Moreover, the process by which money is injected into the economy, that is whether money is injected into the credit market or through lump-sum transfers to agents, exerts no real effect because theory predicts agents to adjust their behaviour such that the interest rate and the allocation of resources remain optimal.

The increase in money through lump-sum transfers vs. credit expansion exerts an asymmetric effect on equilibrium agents' lending decision. In response to lump-sum transfers, theory predicts agents to increase both lending $\left(\partial \bar{M}_{i}^{l} / \partial \bar{M}_{i}>0\right)$ and borrowing $\left(\partial \bar{M}_{i}^{b} / \partial \bar{M}_{i}>0\right)$. By contrast, in response to credit expansion, while theory still predicts agents to increase borrowing $\left(\partial \bar{M}_{i}^{b} / \partial \bar{K}_{i}>0\right)$, it predicts agents to reduce lending $\left(\partial \bar{M}_{i}^{l} / \partial \bar{K}_{i}<0\right)$. This asymmetric effect of credit expansion raises the question of whether the process by which money is injected into the economy matters for the allocation of resources when the economy is populated by homines sapientes rather than homines oeconomici.

\section{The experiment}

We run a laboratory experiment which implements the alternative processes of monetary injection in the economy described above. In this section, we discuss the parameters chosen for each treatment, the corresponding theoretical values, the payoff function, the information provided to participants, and the procedure of the experiment.

\subsection{Parameters}

We conducted four sessions with a total of 72 participants. In each session, the 18 participants were split in three independent groups of six participants (in order to get three independent observations per session and 12 independent observations in total). Each session consisted of three stages and each stage of 15 periods (thus a total of 45 periods per session). Each stage corresponded to a different treatment. Participants played within the same group of participants during the whole length of the experiment and did not know the identity of the other participants of their group.

The choice of parameters for the experiment is summarised in Table 1. The treatments differ from each other in the individual money endowment $M_{i}$ and in the credit expansion per participant $\bar{K}_{i}$. While lump-sum transfers entail an individual increase in money endowment, an increase in money through credit expansion occurs globally (not individually) on the credit market. In the Baseline treatment, the individual money endowment amounts to 100 and the average credit expansion to 0 , so that the overall quantity of money is 600. In the Credit expansion treatment, the individual money endowment amounts to 100 and the credit expansion per participant to 40, so that the overall quantity of money is 840. In the Lump-sum transfers treatment, the individual money endowment amounts to 140 and the credit expansion per participant to 0 , so that the overall quantity of money 
is 840. This parameter choice ensured the comparability of the credit expansion and lump-sum transfers treatments.

The real parameters are the same for the three treatments. The individual input endowment, $L_{i}$, amounts to 20 and the coefficient of the production technology of good 2 , $\beta$, is 0.8. Each of the six participants in a group has a different coefficient in the utility function with $\alpha_{i} \in[0.25,0.35,0.45,0.55,0.65,0.75]$, such that the average coefficient is $\bar{\alpha}=0.5$. The sole difference between groups 1 to 6 (sessions 1 and 2) and groups 7 to 12 (sessions 3 and 4) is the order of play, which aimed at testing order effects.

\begin{tabular}{|c|c|l|c|c|c|c|c|}
\hline Group & Period & Treatment & $M_{i}$ & $\bar{K}_{i}$ & $L_{i}$ & $\beta$ & $\bar{\alpha}$ \\
\hline \hline $1-6$ & $1-15$ & Baseline & 100 & 0 & 20 & 0.8 & 0.5 \\
& $16-30$ & Credit expansion & 100 & 40 & 20 & 0.8 & 0.5 \\
& $31-45$ & Lump-sum transfers & 140 & 0 & 20 & 0.8 & 0.5 \\
\hline $7-12$ & $1-15$ & Baseline & 100 & 0 & 20 & 0.8 & 0.5 \\
& $16-30$ & Lump-sum transfers & 140 & 0 & 20 & 0.8 & 0.5 \\
& $31-45$ & Credit expansion & 100 & 40 & 20 & 0.8 & 0.5 \\
\hline
\end{tabular}

Table 1: Experiment parameters

\subsection{Theoretical values}

Table 2 shows the theoretical values for the three treatments. The interest rate, $r$, and the production of good $1, g_{i, 1}$, and of $\operatorname{good} 2, g_{i, 2}$, are independent of the treatment. The price of input, $p$, of good $1, p_{1}$, and of good $2, p_{2}$ are $40 \%$ higher with credit expansion and lump-sum transfers than in the baseline treatment because there is $40 \%$ more money.

The theoretical amount of money borrowed, $M_{i}^{b}$, is also $40 \%$ higher with credit expansion and lump-sum transfers than in the baseline treatment. However, the theoretical amount of money lent, $M_{i}^{l}$, is lower with credit expansion but higher with lump-sum transfers than in the baseline. The asymmetric response of optimal lending aims at compensating the increase in credit supply due to credit expansion, such that real allocation remains optimal. Periods are theoretically independent of one another because prices are fully flexible and because there is no capital accumulation (or other state variables). The theoretical equilibrium in each period is thus independent of history. However, as is standard in experimental economics, agents adjust their behaviour to previous periods.

\begin{tabular}{|l|c|c|c|c|c|c|c|c|}
\hline Treatment & $r$ & $p$ & $p_{1}$ & $p_{2}$ & $\bar{M}_{i}^{l}$ & $M_{i}^{b}$ & $g_{i, 1}$ & $g_{i, 2}$ \\
\hline \hline Baseline & 0.9 & 5 & 4.50 & 8.71 & 44.44 & 40.00 & 11.11 & 5.74 \\
Credit expansion & 0.9 & 7 & 6.30 & 12.19 & 22.22 & 56.00 & 11.11 & 5.74 \\
Lump-sum transfers & 0.9 & 7 & 6.30 & 12.19 & 62.22 & 56.00 & 11.11 & 5.74 \\
\hline
\end{tabular}

Table 2: Theoretical values 


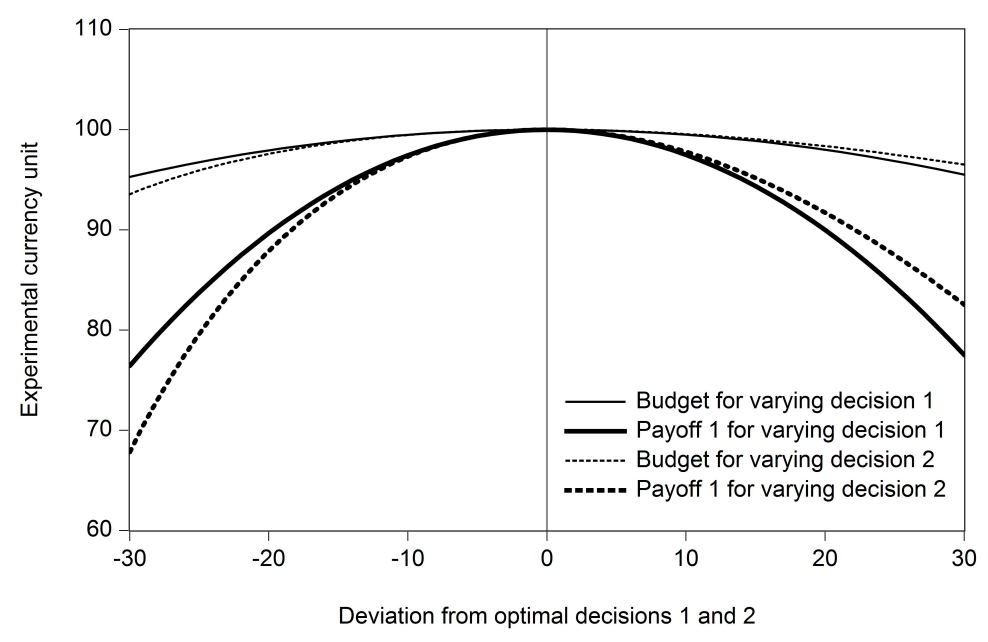

Figure 2: Variation of budget and Payoff ${ }_{i, 1}$ for deviations of decisions 1 and 2

\subsection{Payoff}

As shown above, maximising utility can be split into two separated problems. First, each agent optimises his production to maximise his budget. Second, given his budget, each agent optimises his consumption to maximise his utility. In the experiment, the payoff is also split into two parts to make the effect of decisions on the payoff more explicit. If experimental performance were captured by a single payoff reflecting utility, it would be difficult for participants to identify the impact of each of their three decisions on the single payoff. Splitting the payoff into two parts allows participants to better assess the respective effect of their production and consumption decisions. The unit of payoff is called ECU (experimental currency unit). At the end of each session, the ECU earned were summed up and converted into euros. 350 ECU were converted into 1 euro.

The first part of the payoff captures the budget (8) of each participant, which is driven by the lending and borrowing decisions 1 and 2:

$$
\text { Payoff }_{i, 1}=(\underbrace{g_{i, 1} \cdot p_{1}+g_{i, 2} \cdot p_{2}+r \cdot M_{i}^{l}-M_{i}^{b}+r \cdot \bar{K}_{i}}_{\text {budget (8) }}-M_{i}-\bar{K}_{i}+20) \cdot \frac{M_{i}+\bar{K}_{i}}{20}
$$

The budget is slightly adjusted to amplify the variation of payoffs in response to decisions. Figure 2 illustrates the effect of the adjustment in Payoff ${ }_{i, 1}$. It shows how deviations from optimum of decisions 1 and 2 by one participant affect its budget (8) and Payoff ${ }_{i, 1}$, when the five other participants take optimal decisions. The adjustment raises the incentive of participants to improve their decisions, as it makes deviations from optimum more costly in Payoff ${ }_{i, 1}$ than in budget (8).

The second part of the payoff is determined by the allocation of consumption between good 1 and good 2. Utility derived from the allocation of consumption (1) is translated 


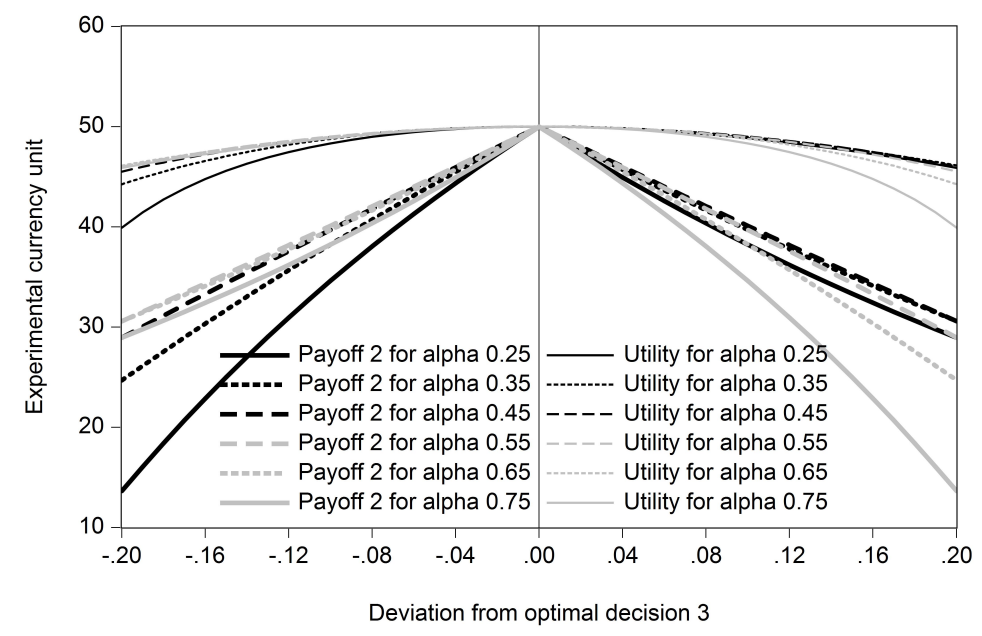

Figure 3: Variation of utility and Payoff ${ }_{i, 2}$ for deviations of decision 3

into ECU as follows:

$$
\operatorname{Payoff}_{i, 2}=\left(1-\frac{\operatorname{abs}\left(\frac{1-\alpha_{i}}{\alpha_{i}} \frac{c_{i, 1}}{c_{i, 2}}-\frac{p_{2}}{p_{1}}\right)}{\frac{1-\alpha_{i}}{\alpha_{i}} \frac{c_{i, 1}}{c_{i, 2}}+\frac{p_{2}}{p_{1}}}\right) \cdot 50
$$

The payoff decreases with the discrepancy between the relative utility and the relative price of goods 1 and 2. Figure 3 illustrates how utility (1) and Payoff ${ }_{i, 2}$ vary with deviations of decision 3 from optimum. ${ }^{7}$ Compared to utility (1), Payoff ${ }_{i, 2}$ yields a greater incentive for participants to improve their decision 3 , as it makes deviations from optimum more costly.

Notice that the adjustments made in Payoff ${ }_{i, 1}$ and Payoff ${ }_{i, 2}$ do not create any bias in the optimal decisions of participants. They simply reinforce the incentive for participants to improve their behavior in line with theoretical predictions. Deviations from theoretical predictions can thus not be the result of a lack of incentive in the lab.

\subsection{Information}

The experiment highlights the role of money prices in the allocation of resources. The information structure of participants is designed to fit with reality as closely as possible. Typically, participants do not know the mathematical expression of their production functions. However, they make their decisions by anticipating the monetary profit of alternative production opportunities. Participants do not know market prices at which they will be able to sell their production and to buy their consumption while making their decisions. However, participants are informed about market prices of previous periods as well as about their previous decisions and payoffs.

\footnotetext{
${ }^{7}$ For the sake of comparison, utility is normalised to reach a maximum of 50 for each value of $\alpha_{i}$.
} 
Participants are informed about the interest rate, $r$, the marginal revenue of the production of good $1, p_{1} / p$, and the marginal revenue of the production of good 2 , $\beta\left(M_{i}^{b} /(r p)\right)^{\beta-1} p_{2} / p$ of the previous periods. This information allows participants to optimise their decisions 1 and 2 .

The relative price of good 2 and good $1, p_{2} / p_{1}$, and the relative marginal utility of consumption of good 2 and $\operatorname{good} 1,\left(1-\alpha_{i}\right) / \alpha_{i} \cdot c_{i, 1} / c_{i, 2}$, are also disclosed to allow participants to optimise their decision 3.

\subsection{Procedure}

Sessions were run in February 2015 at the GATE-LAB of the University of Lyon. Each session had 18 participants who were mainly students from the EM Lyon Business school and the engineering school Ecole Centrale Lyon. Participants were seated in random order at PCs. Instructions were then read aloud and questions answered in private. Throughout the sessions, students were not allowed to communicate with one another and could not see each others' screens. Each participant could only participate in one session. Before starting the experiment, participants were required to answer a few questions to ascertain their understanding of the rules. The experiment started after all participants had given the correct answers to these questions. Examples of instructions, questionnaires, and screens are given in Appendices D, E, and F.

After each period, participants were informed about the market outcome, their partners' decision, and their payoff. Payoffs ranged from 15 to 28 euros. The average payoff was about 22 euros. Sessions lasted for around 90 minutes.

\section{Experimental results}

The results of the experiment are presented as follows. First, an initial impression of the experimental outcome is provided by the realised utility and the decomposition of its deviation from equilibrium into its various sources. Second, the analysis of the consumption allocation shows that, on average, it does not significantly differ from equilibrium. This implies that the consumption allocation cannot account for significant deviations from equilibrium of the production allocation. Third, the analysis focuses on the allocation of resources in the production of goods and on the effect of various processes of monetary injections. Fourth, the redistributive effect of monetary policy across subjects is assessed.

The average decisions realised in each group over all periods of a given treatment are reported in Table 3. The average realised prices and production of goods are reported in Table 5 and Table 6 in Appendix A. These tables also show the average values over all groups and their average deviations from equilibrium values. For simplicity, the three treatments are abbreviated in the text as follows: $\mathrm{B}$ for baseline, $\mathrm{C}$ for credit expansion, and L for lump-sum transfers.

The average decisions realised in each period over all groups are reported in Figure 4 and the average production of goods in Figure 5. The average realised prices are reported 

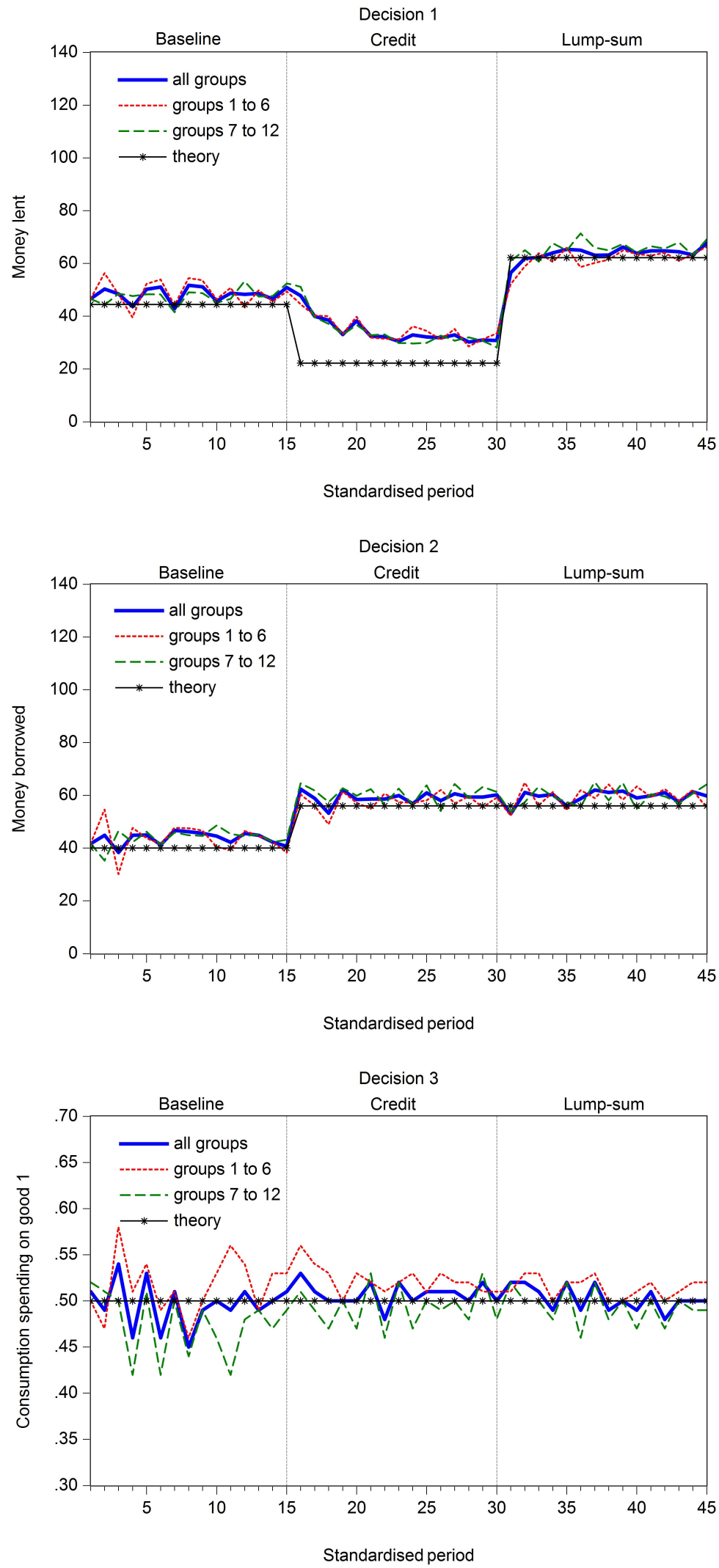

Figure 4: Average realised decisions 
in Figure 12 in Appendix A. Since no effect of treatment order is observed between groups 1 to 6 and 7 to 12, data from all groups are pooled together for analysis. ${ }^{8}$ For the sake of comparison, the period numbers of $\mathrm{C}$ and L for groups 7 to 12 are interchanged. In all figures (except Figure 8), the period numeration is standardised such that periods 16 to 30 refer to $\mathrm{C}$ (and periods 31 to 45 to L) for all groups, although groups 7 to 12 played $\mathrm{C}$ in periods 31 to 45 .

\section{$4.1 \quad$ Realised utility}

Realised utility converges towards equilibrium, suggesting that subjects learn and improve their behaviour over periods. Figure 6 plots the average realised utility expressed as percentage of equilibrium utility over the 45 periods of the experiment. It also decomposes the percentage deviation from equilibrium utility into its various sources. The dotted line illustrates the utility loss due to deviations of decision 1 from equilibrium, the dashed line the utility loss due to deviations of decision 2 , and the solid line the utility loss due to deviations of decision 3 .

Consumption decision is responsible for the largest share of utility loss. Deviations of decision 3 from equilibrium, however, rapidly decrease over all periods. By contrast, whereas the utility loss due to the lending decision 1 seems to decrease over periods in B, it clearly increases again in C, but not in L. Finally, deviations of borrowing decision 2 do not substantially reduce realised utility, though the related utility loss declines over

\begin{tabular}{|c||c|c|c||c|c|c||c|c|c|}
\hline \multicolumn{1}{|c||}{} & \multicolumn{3}{c||}{$M_{i}^{l}$} & \multicolumn{3}{c||}{$M_{i}^{b}$} & \multicolumn{3}{c|}{$s_{i}$} \\
& $\mathrm{~B}$ & $\mathrm{C}$ & $\mathrm{L}$ & $\mathrm{B}$ & $\mathrm{C}$ & $\mathrm{L}$ & $\mathrm{B}$ & $\mathrm{C}$ & $\mathrm{L}$ \\
\hline Group 1 & 52.26 & 34.43 & 63.28 & 46.06 & 54.02 & 56.94 & 0.53 & 0.55 & 0.51 \\
\hline Group 2 & 46.48 & 31.72 & 51.57 & 42.60 & 51.76 & 55.19 & 0.55 & 0.57 & 0.56 \\
\hline Group 3 & 52.25 & 37.98 & 60.84 & 44.98 & 60.53 & 56.37 & 0.49 & 0.52 & 0.54 \\
\hline Group 4 & 47.29 & 35.44 & 64.15 & 43.63 & 65.84 & 62.45 & 0.51 & 0.50 & 0.51 \\
\hline Group 5 & 48.00 & 35.64 & 66.00 & 41.61 & 58.70 & 62.94 & 0.50 & 0.49 & 0.49 \\
\hline Group 6 & 47.57 & 33.64 & 65.33 & 41.81 & 55.09 & 63.17 & 0.52 & 0.51 & 0.49 \\
\hline Group 7 & 49.23 & 30.85 & 62.93 & 42.59 & 54.81 & 53.88 & 0.49 & 0.50 & 0.51 \\
\hline Group 8 & 48.55 & 33.88 & 68.08 & 47.52 & 59.36 & 59.69 & 0.46 & 0.49 & 0.47 \\
\hline Group 9 & 45.24 & 37.19 & 68.67 & 47.75 & 65.92 & 65.66 & 0.49 & 0.53 & 0.52 \\
\hline Group 10 & 47.65 & 34.97 & 67.23 & 42.48 & 60.39 & 58.70 & 0.45 & 0.44 & 0.45 \\
\hline Group 11 & 45.41 & 34.59 & 62.53 & 39.68 & 62.11 & 58.84 & 0.50 & 0.50 & 0.50 \\
\hline Group 12 & 49.99 & 31.30 & 64.54 & 43.03 & 61.30 & 59.65 & 0.46 & 0.49 & 0.51 \\
\hline Average & $\mathbf{4 8 . 3 3}$ & $\mathbf{3 4 . 3 0}$ & $\mathbf{6 3 . 7 6}$ & $\mathbf{4 3 . 6 5}$ & $\mathbf{5 9 . 1 5}$ & $\mathbf{5 9 . 4 6}$ & $\mathbf{0 . 5 0}$ & $\mathbf{0 . 5 1}$ & $\mathbf{0 . 5 0}$ \\
\hline Deviation & $\mathbf{3 . 8 9}$ & $\mathbf{1 2 . 0 8}$ & $\mathbf{1 . 5 4}$ & $\mathbf{3 . 6 5}$ & $\mathbf{3 . 1 5}$ & $\mathbf{3 . 4 6}$ & $\mathbf{- 0 . 0 0}$ & $\mathbf{0 . 0 1}$ & $\mathbf{0 . 0 0}$ \\
\hline
\end{tabular}

Table 3: Realised decision $1 M_{i}^{l}$, decision $2 M_{i}^{b}$, and decision $3 s_{i}$. B: baseline, C: credit expansion, L: lump-sum transfers.

\footnotetext{
${ }^{8}$ Mann-Whitney tests do not show any order effect on the behaviour of subjects. First, decisions 1,2 , and 3 under $\mathrm{C}$ in groups 1 to 6 are not different from those in groups 7 to 12 ( $p=0.471, p=0.173$, and $p=0.123$ respectively). Second, decisions 1, 2, and 3 under L in groups 1 to 6 are not different from those in groups 7 to $12(p=0.173, p=0.936$, and 0.369$)$.
} 

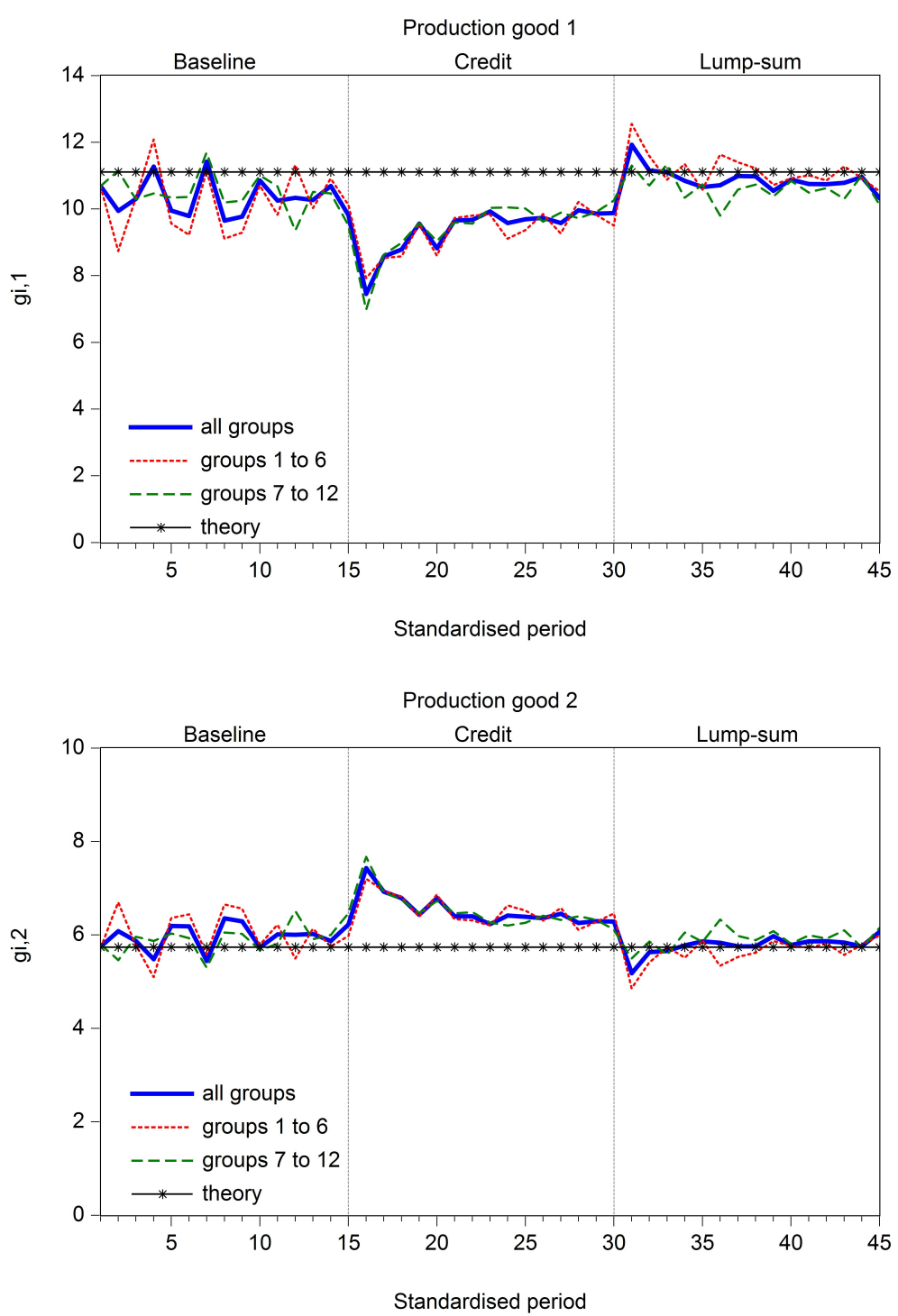

Figure 5: Average realised productions

periods.

It is important to emphasise the interrelation between decisions in the determination of outcome: price effect due to deviations in one decision may trigger deviations in other decisions. For example, if the demand for consumption of good 2 from decision 3 is above equilibrium, the relatively higher price of good 2 may induce subjects to raise their borrowing decision 2 above equilibrium to increase their production of good 2. In turn, higher borrowing may raise interest rate and induce subjects to increase their lending decision 1 above equilibrium as well.

Decision 1 (lending) establishes the aggregate allocation of resources between the production of good 1 and good 2 because the money lent determines the money effectively 


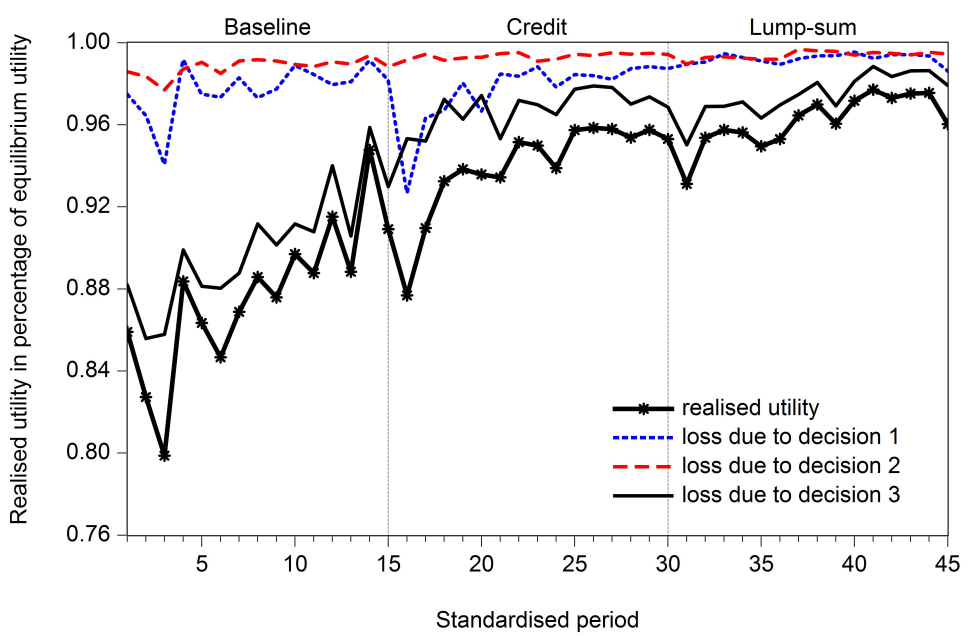

Figure 6: Realised utility in percentage of equilibrium utility; utility loss decomposed by decision errors

borrowed, as interest rate clears the credit market. It also drives the production of good 1 by each subject. Decision 2 (borrowing) drives the distribution of production of good 2 across subjects. It influences the aggregated production of good 2 only insofar as an uneven distribution of production of good 2 across subjects reduces the aggregated production because of decreasing marginal productivity. Decision 3 (consumption) determines the demand for good 1 and good 2, and influences the relative price of these goods, which drives the incentive for producing goods.

For disentangling the intertwined causes of equilibrium deviations, the next section analyses consumption allocation and shows that it cannot account for deviations in production allocation.

\subsection{Consumption allocation}

The allocation of consumption determines the relative demand for good 1 and good 2, their relative price, and thereby the incentive to allocate input for production. We first compare the average consumption decision with theory and then split consumption decisions across consumption preferences.

\subsubsection{Comparison with theory}

The average realisation of decision 3 yields the following result:

Result 1 On average, the consumption decision 3 does not significantly deviate from equilibrium in all treatments. The average allocation of consumption, thus, cannot be accounted for significant deviations from the equilibrium allocation of production. 
Support Mann-Whitney tests do not reject the hypothesis that the average proportion of revenue spent on consumption of good 1 is not significantly different from the equilibrium value in all treatments ( $p=0.975$ in $\mathrm{B}, p=0.975$ in $\mathrm{C}$, and $p=0.147$ in $\mathrm{L}$ ). Figure 4, lower panel, offers a visual representation of the fact that the average decision 3 realised in the experiment does not systematically deviate from equilibrium. Moreover, consumption decision 3 does not account for any systematic deviation of realised prices from equilibrium. Figure 7 illustrates how price deviations from equilibrium are decomposed into their various sources, that is into the three decisions of the experiment. The middle and lower panels indicate that decision 3 yields no systematic deviation from the theoretical price of good 1 and good 2 .

\subsubsection{Comparison across parameters $\alpha_{i}$ and convergence}

Equilibrium consumption decision 3 is determined by the parameter $\alpha_{i}$ of the CobbDouglas consumption function (1), with $s_{i}=\alpha_{i}$ as derived in section 2.2.5. The realised consumption allocation is analysed for each parameter $\alpha_{i}$ separately. Figure 13 in Appendix $\mathrm{C}$ plots the distribution of decisions 3 (third line) over all periods for each parameter $\alpha_{i}$ in the three treatments.

Result 2 The individual allocation of consumption deviates from equilibrium in the early periods of the experiment but converges towards equilibrium over time. Deviations of individual consumption allocation are larger for extreme parameters $\alpha_{i}$.

Support Figure 8 illustrates deviations of decision 3 from the equilibrium value, measured as $\bar{s}_{i, t \mid \alpha_{i}}-\alpha_{i}$, for each of the six values of $\alpha_{i} .{ }^{9}$ Deviations are positive for $\alpha$-values smaller than 0.5 and negative for $\alpha$-values larger than 0.5. Deviations are larger for extreme values of $\alpha_{i}$ and decrease over periods, indicating that decision 3 goes in the direction predicted by theory. In the last periods of the experiment, even for extreme values of $\alpha_{i}$, deviations from equilibrium get weaker than in the first periods. The Mann trend test identifies a significant downwards trend for $\alpha_{i}=0.25(p=0.000)$ and $\alpha_{i}=0.35(p=0.000)$, a significant upwards trend for $\alpha_{i}=0.65(p=0.002)$ and $\alpha_{i}=0.75(p=0.000)$, but no significant trend for $\alpha_{i}=0.45(p=0.312)$ and $\alpha_{i}=0.55(p=0.264)$.

Following Noussair et al. (1995), ${ }^{10}$ convergence is assessed with the regression

$$
\bar{s}_{i, t \mid \alpha_{i}}=Z_{1} / t+Z_{2}(t-1) / t+u
$$

where $\bar{s}_{i, t \mid \alpha_{i}}$ is the average decision 3 of subjects with $\alpha_{i}$ at period $t, Z_{1}$ is the starting value of a possible convergence process, $Z_{2}$ is the asymptote of the convergence, and $u$

\footnotetext{
${ }^{9}$ Figure 8 reports data in the original sequence of play. Periods 16 to 30 correspond to $\mathrm{C}$ for groups 1 to 6 and to L for groups 7 to 12. Periods 31 to 45 correspond to L for groups 1 to 6 and to $\mathrm{C}$ for groups 7 to 12 .

${ }^{10}$ We use a slightly modified specification: while Noussair et al. (1995) allow for different starting values of a possible convergence process that measure different origins of the data for their different experimental sessions, we assume a common starting value $Z_{1}$ for all groups.
} 

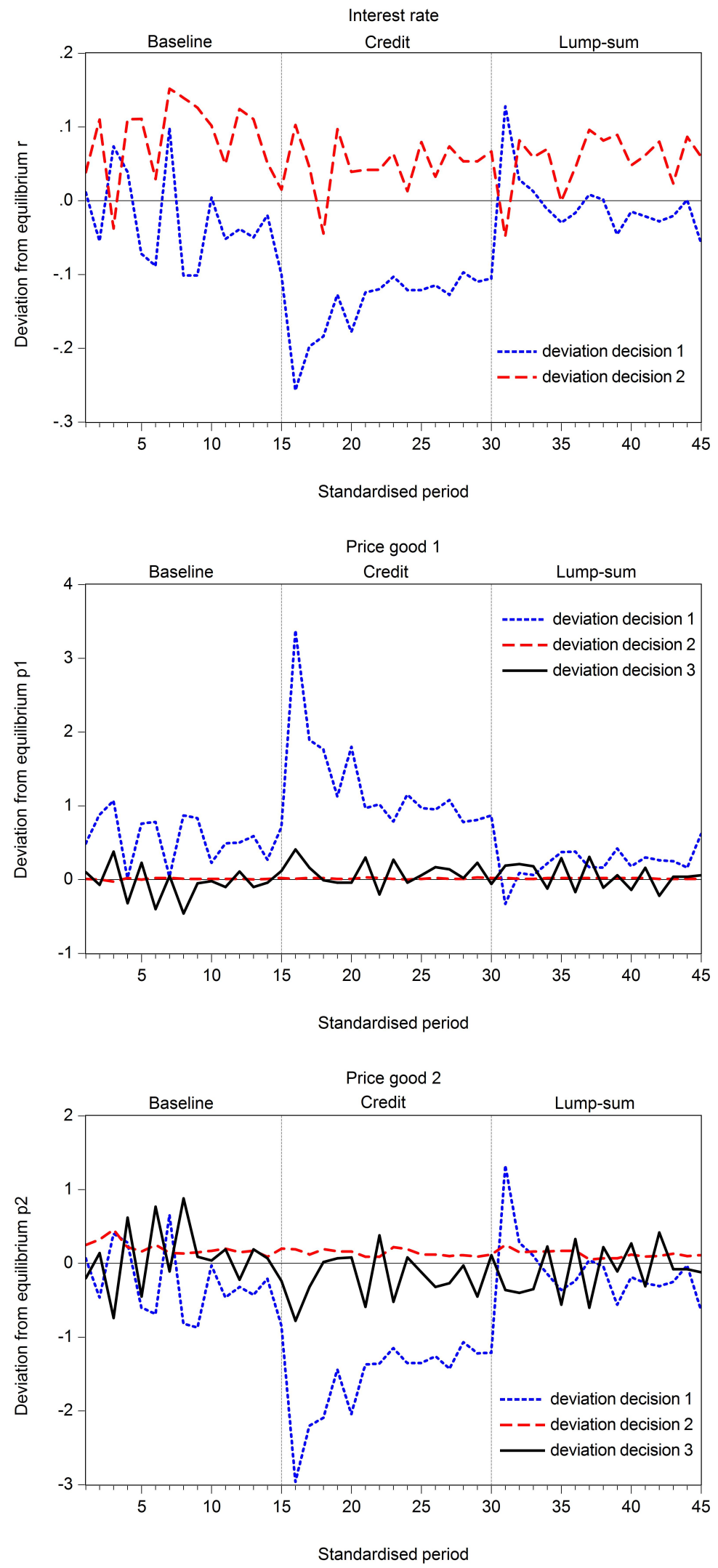

Figure 7: Decomposition of price deviation by decision 


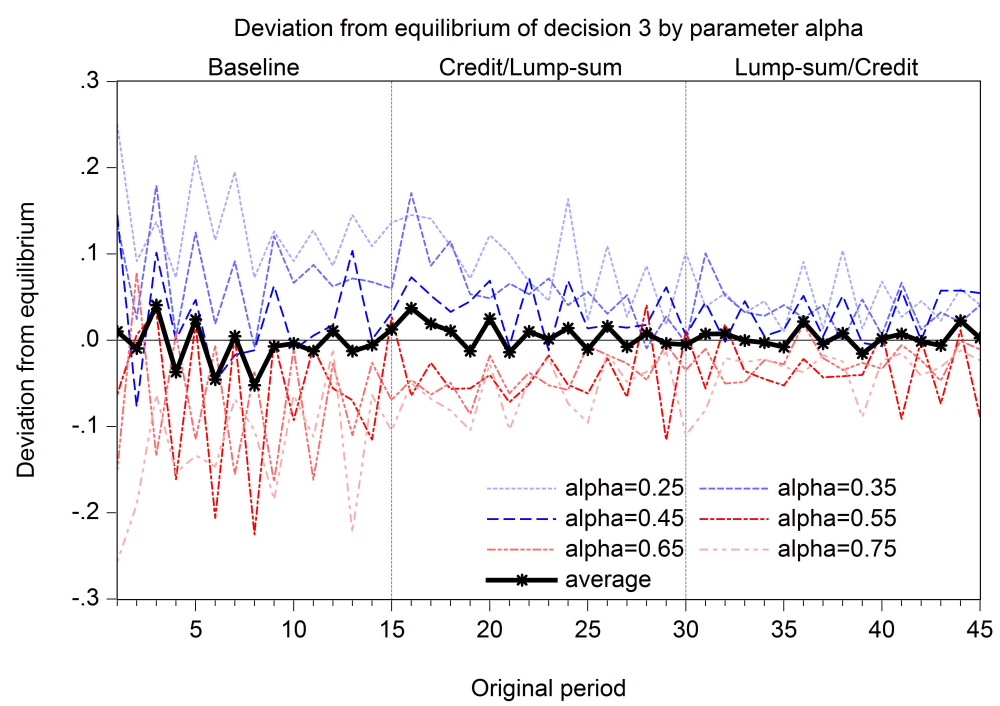

Figure 8: Average deviation from equilibrium of decision 3

is the normally distributed random error term. As shown on Table 7 in Appendix B, whereas the starting values $Z_{1}$ are close to 0.5 for all values of $\alpha_{i}$, the asymptote values $Z_{2}$ approach the respective values of $\alpha_{i}$.

To sum up, whereas Result 2 states that deviations of consumption decision from equilibrium yield a suboptimal allocation of consumption across individuals and, thereby, a utility loss (illustrated in Figure 6), Result 1 shows that the average consumption decision cannot explain deviations in the production allocation.

\subsection{Production allocation}

The allocation of production is first compared with theoretical predictions; then the effect of treatments on the allocation is analysed.

\subsubsection{Comparison with theory}

The allocation of resources in the economy can be assessed along three intertwined dimensions: decisions of subjects (plotted in Figure 4), market prices (plotted in Figure 12 in Appendix A), and production of goods (plotted in Figure 5). We compare production and prices with theory, and then focus on subjects' decisions.

Result 3 The production of good 1 is statistically lower than equilibrium and the price of good 1 higher than its theoretical value in all treatments. The production of good 2 is higher than equilibrium in $\mathrm{B}$ and $\mathrm{C}$, but not different from equilibrium in L. The price of good 2 is lower than its theoretical value in $\mathrm{C}$, but not different from equilibrium in $\mathrm{B}$ and in $\mathrm{L}$. 

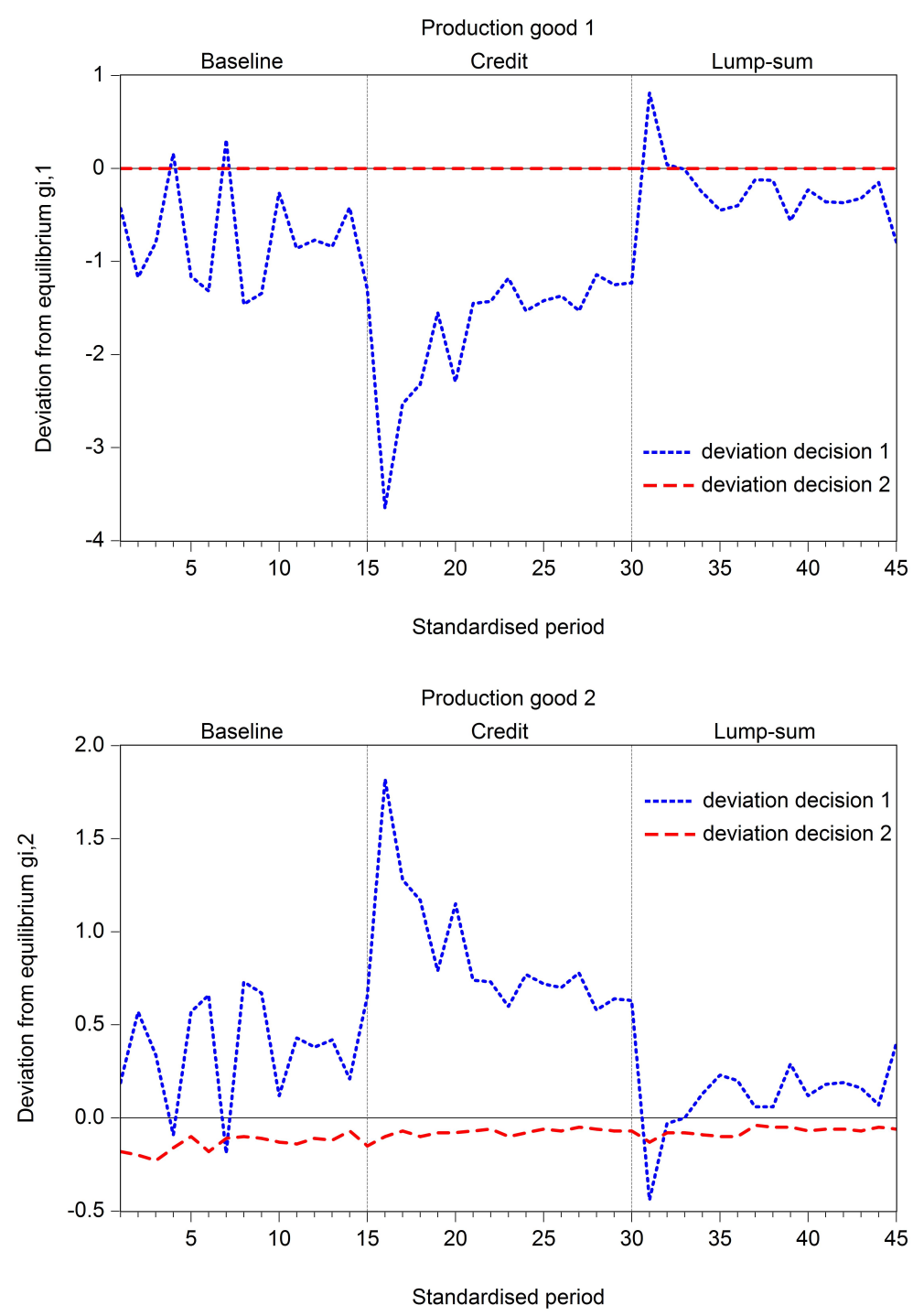

Figure 9: Decomposition of production deviation by decision

Support Mann-Whitney tests reveal that the production of good 1 is significantly smaller than theoretically predicted in all treatments, $(p=0.000$ in $\mathrm{B}, p=0.000$ in $\mathrm{C}$, and $p=0.003$ in $\mathrm{L})$. The production of good 2 is significantly larger in $\mathrm{B}(p=0.003)$ and $\mathrm{C}(p=0.000)$, but it is not significantly different from the theoretical prediction in $\mathrm{L}(p=0.478)$. Accordingly, the price of good 1 is significantly higher than theoretically predicted in all treatments $(p=0.000$ in $\mathrm{B}, p=0.000$ in $\mathrm{C}$, and $p=0.003$ in L). While the price of good 2 is significantly lower than theoretically predicted in $\mathrm{C}(p=0.000)$, it does not significantly differ from theory in $\mathrm{B}(p=0.478)$ and $\mathrm{L}(p=0.441)$.

Result 4 When initial deviations are large, production allocations and prices converge towards their equilibrium values. 
Support Figure 5 illustrates the development of production of goods 1 and 2 compared to their equilibrium value for each treatment. In the upper panel, production of good 1 is slightly below theoretical value in B, strongly below in C, and close to theory in L. For the largest deviation from theory (in $\mathrm{C}$ ), deviations from theory get weaker period after period. In the lower panel, production of good 2 is slightly above theoretical value in $\mathrm{B}$, strongly above in $\mathrm{C}$ and close to theory in L. The largest deviation from theory (in C) gets weaker period after period.

While no trend is observed in $\mathrm{B}$ ( $p=0.421$ for the production of good 1 and $p=0.755$ for the production of good 2), the Mann trend test identifies in $\mathrm{C}$ a significant upwards trend for the production of good $1(p=0.000)$ and a significant downwards trend for the production of good $2(p=0.001)$. In $\mathrm{L}$, there is a significant downwards trend in the production of good $1(p=0.015)$ and a significant upwards trend in the production of good $2(p=0.004)$.

Figure 12 in Appendix A illustrates the development of the interest rate and prices of goods 1 and 2 compared to their equilibrium value for each treatment. In the upper panel, interest rate is slightly above theoretical value in B, strongly below in C, and slightly above in L. For the largest deviation from theory (in C), deviations get weaker period after period. In the middle panel, price of good 1 is slightly above theoretical value in $\mathrm{B}$ and in L, but strongly above theoretical value in C. The largest deviation from theory (in C) gets weaker period after period. In the lower panel, price of good 2 is close to theory in $\mathrm{B}$ and in $\mathrm{L}$, but strongly below in $\mathrm{C}$.

While no trend is observed in $\mathrm{B}$ and $\mathrm{L}$ for the interest rate $(p=0.278$, and $p=0.069$ respectively), for the price of good 1 ( $p=0.312$, and $p=0.278$ respectively), and for the price of good $2(p=0.217$, and $p=0.084$ respectively), the Mann trend test identifies in $\mathrm{C}$ a significant upwards trend for the interest rate $(p=0.009)$ and for the price of good 2 $(p=0.009)$ and a significant downwards trend for the price of good $1(p=0.005)$.

As in section 4.2, convergence is addressed for both production of good 1 and production of good 2 with the regression (13). As shown on Table 8 in Appendix B, the starting values $Z_{1}$ in $\mathrm{C}$ are rather far from theoretical values, but the asymptote values $Z_{2}$ approach these values. Table 9 in Appendix B shows that the starting values $Z_{1}$ in $\mathrm{C}$ for the interest rate, price of good 1 , and price of good 2 are rather far from theoretical values, but the asymptote values $Z_{2}$ approach the these values.

Analysing the cause for deviations in the production allocation and prices delivers the following result:

Result 5 Deviations in production allocation and prices from equilibrium are essentially caused by the lending decision 1 , rather than by the borrowing decision 2 .

Support Figure 9 decomposes deviations in production of goods 1 and 2 into deviations in decisions 1 and 2. The upper panel shows that deviations in the production of good 1 are exclusively accounted for by deviations in the lending decision 1 . This arises because 
decision 1 determines the aggregate allocation of input between the production of good 1 and good 2 since the interest rate clears the credit market. The borrowing decision 2 drives the distribution of production of good 2 across subjects and affects its aggregated production only because of decreasing marginal productivity. The lower panel shows that deviations in decision 2 reduce the production of good 2 , but only marginally compared to the impact of deviations in decision 1.

Alternatively, Figure 7 decomposes deviations in prices into deviations in decisions 1 and 2. Deviations in prices are mainly driven by deviations in decision 1 , while deviations in decision 2 have only a subdued effect.

Figure 13 in Appendix $\mathrm{C}$ shows that the utility preference parameter $\alpha_{i}$ does not influence decisions 1 and 2 of participants, in accordance with theory. Choices of production are independent of the consumption preference.

\subsubsection{Comparison between treatments}

According to the theoretical model, the process by which money is injected into the economy exerts no influence on the allocation of resources. As reported in Table 2, theory predicts subjects to adjust their behaviour to monetary injection such that allocation remains unaffected. The increase in money in L yields a parallel increase in lending and borrowing decisions because it affects all markets evenly. By contrast, the increase in money in $\mathrm{C}$ requires a reduction in lending but an increase in borrowing because money is exclusively injected into the credit market. Such an asymmetry may be the source of differences in behavior. Indeed, comparing the realised allocations in the experiment, the following result can be stated:

Result 6 Deviations in production allocation from equilibrium are substantially larger in $\mathrm{C}$ than in $\mathrm{L}$. The larger deviation in $\mathrm{C}$ is attributable to the asymmetric effect that credit expansion exerts on lending vs. borrowing decisions. In $\mathrm{C}$ subjects do not reduce their lending as much as theory predicts.

Support Figures 4, 5, 6, and 12 show that deviations from equilibrium are substantially larger in $\mathrm{C}$ than in $\mathrm{L}^{11}$ Larger deviations from equilibrium observed in $\mathrm{C}$ can be rationalised by the asymmetric effect that credit expansion exerts on equilibrium decisions. Figure 10 provides an illustration on individual data. It plots the relative frequency of the realised difference between lending (decision 1) and borrowing (decision 2). The figure also shows the average realised difference and the equilibrium difference. While the realised difference between decision 1 and decision 2 largely coincides with theoretical predictions in $\mathrm{B}$ and $\mathrm{L}$, the average difference is substantially larger than the equilibrium difference in C. Although subjects reduce their lending decision 1 in $\mathrm{C}$ in accordance with theoretical

\footnotetext{
${ }^{11}$ Wilcoxon matched-pairs signed-rank tests reveal that the production of good 1 in $\mathrm{B}$ is significantly larger than in $\mathrm{C}(p=0.003)$ but smaller than in $\mathrm{L}(p=0.025)$, and that in $\mathrm{C}$ smaller than that in $\mathrm{L}$ $(p=0.003)$. The production of good 2 in B is significantly smaller than in $\mathrm{C}(p=0.003)$ but not different from that in $\mathrm{L}(p=0.290)$, and that in $\mathrm{C}$ is larger than that in $\mathrm{L}(p=0.003)$.
} 

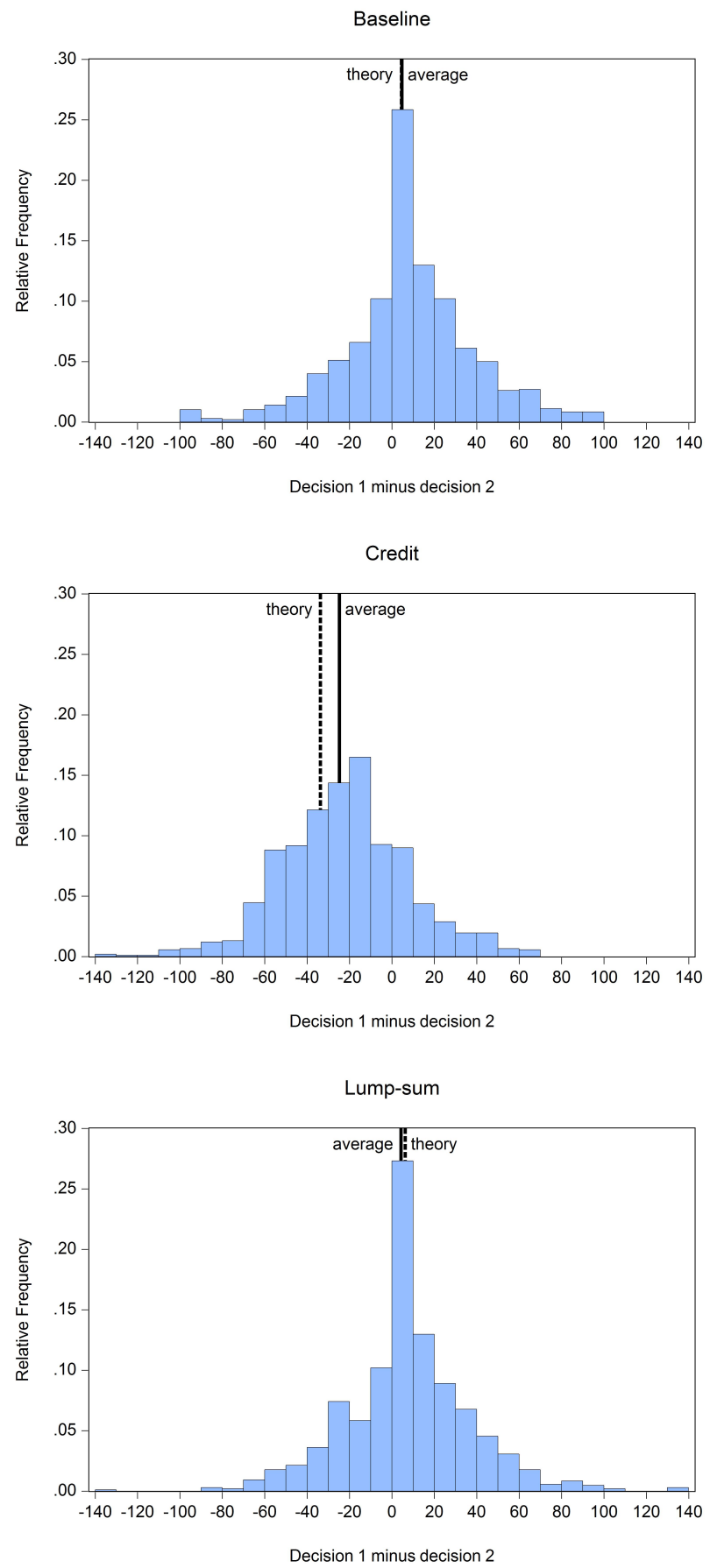

Figure 10: Relative frequency of decision 1 minus decision 2 
prediction, they do not reduce lending as much as theory predicts. Therefore, deviations from theory in the lending decision in $\mathrm{C}$ lead to stronger distortions in interest rates, prices and production of goods 1 and 2. Deviations, however, decrease over periods, as highlighted in Result 4.

The reason for the large deviations from equilibrium in $\mathrm{C}$ may be that subjects find the optimal lending decision 1 counter-intuitive. Subjects may experience some difficulties in taking the optimal lending decision 1 in $\mathrm{C}$ because an increase in the quantity of money by means of $\mathrm{C}$ calls - perhaps counter-intuitively - for a reduction in lending. The net optimal lending position of $4.44(44.44-40)$ in B turns into a net optimal borrowing position of $-33.78(22.22-56)$ in $\mathrm{C}$. By contrast, an increase in money by means of $\mathrm{L}$ merely raises the net optimal lending position proportionally to the money increase to $6.22(62.22-56)$. Since an increase in money in L affects all markets evenly, subjects do not need to re-assess their net optimal lending position in response to an increase in the quantity of money.

\subsection{Redistributive effect of monetary injection}

Deviations from equilibrium induced by $\mathrm{C}$ exert a redistributive effect across subjects because of different utility preferences $\alpha_{i}$.

Result 7 As $\mathrm{C}$ stimulates the production of good 2 above equilibrium, it improves utility of subjects with a high marginal utility of consuming good 2 and deteriorates utility of subjects with a low marginal utility of consuming good 2 .

Support The relative price $p_{2} / p_{1}$ influences subjects' utility differently according to their utility parameter $\alpha_{i}$. A higher relative price tends to deteriorate utility of subjects with a high preference for good 2 , that is with a low $\alpha_{i}$. We regress the utility of subjects with a given parameter $\alpha_{i}$ on a constant and on the deviation of relative price from

equilibrium: $U_{i, t \mid \alpha}=$ const $+\omega\left(\frac{p_{2, t}}{p_{1, t}}-\frac{p_{2}^{*}}{p_{1}^{*}}\right)$. Table 4 shows that higher relative prices significantly reduce utility of subjects with a high consumption preference for good 2 $\left(\alpha_{i}=0.25\right.$ and $\left.\alpha_{i}=0.35\right)$, but significantly improve utility of subjects with a high consumption preference for good $1\left(\alpha_{i}=0.65\right.$ and $\left.\alpha_{i}=0.75\right)$.

\begin{tabular}{l|cccccc} 
& $\alpha=0.25$ & $\alpha=0.35$ & $\alpha=0.45$ & $\alpha=0.55$ & $\alpha=0.65$ & $\alpha=0.75$ \\
\hline const & -0.30 & -0.20 & -0.47 & -1.12 & -0.77 & -0.79 \\
& $(0.00)$ & $(0.00)$ & $(0.00)$ & $(0.00)$ & $(0.00)$ & $(0.00)$ \\
$\omega$ & -0.50 & -0.25 & -0.06 & -0.25 & 0.20 & 0.70 \\
& $(0.00)$ & $(0.00)$ & $(0.33)$ & $(0.01)$ & $(0.01)$ & $(0.00)$ \\
$R^{2}$ & 0.13 & 0.04 & 0.00 & 0.02 & 0.01 & 0.11 \\
\hline
\end{tabular}

Table 4: Effect of relative price deviation on utility by parameter $\alpha_{i}$. P-values in parentheses. 


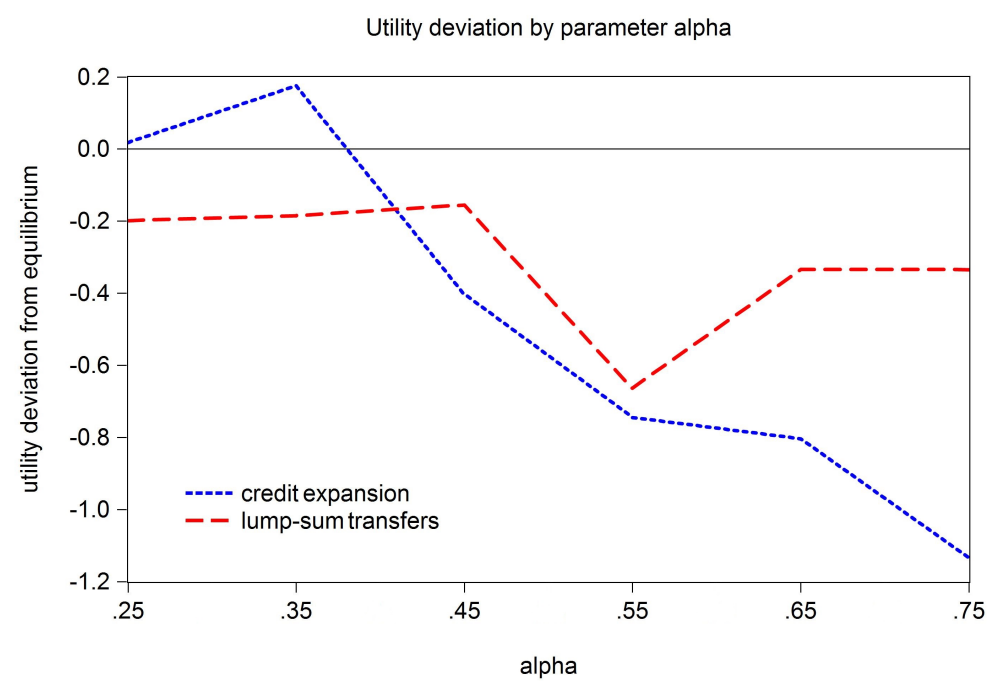

Figure 11: Redistributive effect of credit expansion

As $\mathrm{C}$ stimulates the production of good 2 and lowers the relative price $p_{2} / p_{1}$, it tends to improve the utility of subjects with low $\alpha_{i}$. Figure 11 plots the utility deviation from equilibrium for each parameter $\alpha_{i}$. Deviations for $\alpha_{i}=0.25$ and $\alpha_{i}=0.35$ are positive in $\mathrm{C}$, indicating that the average utility of subjects with a high preference for good 2 is higher than in equilibrium. Alternatively, the average utility of subjects with a low preference for good 2 is reduced in $\mathrm{C}$. By contrast, there is no clear-cut redistributive effect in $\mathrm{L}$.

\section{Conclusion}

We conduct a laboratory experiment on a monetary general equilibrium economy to assess the allocative effect of monetary policy. The experiment builds on a theoretical model that gives a causal-realistic role for money in every economic transaction. The allocation of real resources results from the money spent by agents on the different markets. In that respect, our model fundamentally departs from the mainstream literature where money if not ignored - plays only a trivial role in economic exchanges.

Two processes of monetary injection are implemented: credit expansion and lumpsum monetary transfers. Credit expansion captures the process of monetary injection currently in place in today's economies, where money is created through the granting of credit. Lump-sum transfers, by contrast, stand for another possible scheme of monetary injection where the increase in money in circulation occurs evenly across all individuals and independently of the course of the credit market.

Although the theoretical model predicts, in line with mainstream economics, that the process of monetary injection is irrelevant and neutral, the experiment shows that credit expansion exerts a significant distortionary effect on resource allocation. The intuition for 
such a result is associated with the asymmetric effect credit expansion exerts in comparison to lump-sum transfers: while subjects should increase both lending and borrowing in the case of lump-sum transfers, they should increase borrowing but reduce lending in response to credit expansion, making it harder to adjust their behavior in the lab. Credit expansion also has a redistributive effect across subjects in favor of those who have a high consumption preference for the good whose production is stimulated by credit. The allocative effect of credit expansion comes from the fact that the increase in money is injected into the credit market, whereas lump-sum transfers affect all sectors evenly.

This finding is reminiscent of the insights of Cantillon (1755), who emphasised that an increase in money primarily affects relative prices rather than all prices to the same extent because money enters the economy at a certain point. This suggests that the current monetary system exerts a distortionary effect on the real economy as money is created through the granting of credit. Our analysis invites economists to reconsider the design of the monetary system while accounting for its economic consequences. In particular, processes of monetary injection should be assessed according to their reallocation effect. In an ideal world, an increase in the quantity of money should exert no distortionary effect on real allocation. Lump-sum transfers to citizens is perhaps the process that comes closest to this quest.

Our experiment is very simple and can be extended in many ways. As it is confined to a repeated static model, a natural extension would be to play a monetary economy with interrelated periods and with a stock of capital in order to assess the effect of monetary policy on the economic dynamics. We leave this investigation to future research.

\section{References}

Baron, M. and Xiong, W. (2017). Credit expansion and neglected crash risk. The Quarterly Journal of Economics, pages 713-764.

Borio, C. and Lowe, P. (2002). Asset prices, financial and monetary stability: Exploring the nexus. BIS Working Paper.

Bosch-Domenech, A. and Silvestre, J. (1997). Credit constraints in general equilibrium: Experimental results. The Economic Journal, 107(444):1445-1464.

Calvo, G. A. (1983). Staggered prices in a utility maximizing framework. Journal of Monetary Economics, 12:383-398.

Camera, G. and Casari, M. (2014). The coordination value of monetary exchange: Experimental evidence. American Economic Journal: Microeconomics, 6(1):290-314.

Cantillon, R. (1755). "Essai sur la nature du commerce en général". Fletcher Gyles, London.

Duffy, J. and Ochs, J. (1999). Emergence of money as a medium of exchange: An experimental study. American Economic Review, 89:847-877. 
Duffy, J. and Puzzello, D. (2014). Gift exchange versus monetary exchange: Theory and evidence. American Economic Review, 104(6):1735-1776.

Fehr, E. and Tyran, J.-R. (2001). Does money illusion matter? American Economic Review, 91:1239-1262.

Fehr, E. and Tyran, J.-R. (2008). Limited rationality and strategic interaction: The impact of the strategic environment on nominal inertia. Econometrica, 76:353-394.

Friedman, M. (1960). A Program for Monetary Stability. Fordham University Press, New York.

Hayek, F. A. v. (1928). Das intertemporale Gleichgewichtssystem der Preise und die Bewegungen des Geldwertes. Weltwirtschaftliches Archiv, 28:33-76.

Krainer, R. E. (2017). Economic stability under alternative banking systems: Theory and policy. Journal of Financial Stability, 31:107-118.

Kryvtsov, O. and Petersen, L. (2013). Expectations and monetary policy: Experimental evidence. Bank of Canada, Working Paper, 44.

Ledoit, O. (2011). The redistributive effects of monetary policy. University of Zurich Working Paper Series, 44.

Lian, P. and Plott, C. (1998). General equilibrium, markets, macroeconomics and money in a laboratory experimental environment. Economic Theory, 12:21-75.

Lucas, R. E. J. (1972). Expectations and the neutrality of money. Journal of Economic Theory, 4:103-124.

Mankiw, N. G. and Reis, R. (2002). Sticky information versus sticky prices: A proposal to replace the new keynesian phillips curve. The Quarterly Journal of Economics, $117: 1295-1328$.

McLeay, M., Radia, A., and Thomas, R. (2014). Money creation in the modern economy. Bank of England Quarterly Bulletin Q1.

Mises, L. v. (1912). "The Theory of Money and Credit". [Reprint by Liberty Fund, Indianapolis, 1981], Vienna.

Noussair, C. N., Pfajfar, D., and Zsiros, J. (2014). Frictions, persistence, and central bank policy in an experimental dynamic stochastic general equilibrium economy. In Duffy, J., editor, Experiments in Macroeconomics, Research in Experimental Economics. Emerald Press.

Noussair, C. N., Plott, C. R., and Riezman, R. G. (1995). An experimental investigation of the patterns of international trade. American Economic Review, 83(3):462-491.

Petersen, L. (2015). Do expectations and decisions respond to monetary policy? 
Phelps, E. S. (1970). Introduction: The new microeconomics in employment and inflation theory. In Microeconomic Foundations of Employment and Inflation Theory, 1-23. Norton, New York.

Rotemberg, J. J. (1982). Monopolistic price adjustment and aggregate output. Review of Economic Studies, 44(4):517-531.

Schularick, M. and Taylor, A. (2012). Credit booms gone bust: Monetary policy, leverage cycles and financial crises, 1870-2008. American Economic Review.

Turner, A. (2015). "Between Debt and the Devil: Money, Credit, and Fixing Global Finance". Princeton University Press, Princeton, New Jersey. 


\section{A Realised prices and production}

\begin{tabular}{|c||c|c|c||c|c|c||c|c|c|}
\hline \multicolumn{1}{|l||}{} & \multicolumn{3}{c||}{$r$} & \multicolumn{3}{c||}{$p_{1}$} & \multicolumn{3}{c|}{$p_{2}$} \\
& $\mathrm{~B}$ & $\mathrm{C}$ & $\mathrm{L}$ & $\mathrm{B}$ & $\mathrm{C}$ & $\mathrm{L}$ & $\mathrm{B}$ & $\mathrm{C}$ & $\mathrm{L}$ \\
\hline Group 1 & 0.94 & 0.74 & 0.93 & 6.06 & 8.22 & 6.69 & 8.01 & 10.06 & 12.02 \\
\hline Group 2 & 0.96 & 0.74 & 1.10 & 5.40 & 8.39 & 6.22 & 7.94 & 9.63 & 13.14 \\
\hline Group 3 & 0.89 & 0.78 & 0.95 & 5.42 & 8.36 & 6.74 & 8.19 & 10.07 & 11.75 \\
\hline Group 4 & 0.98 & 0.88 & 0.99 & 4.98 & 7.67 & 6.65 & 8.75 & 10.76 & 12.03 \\
\hline Group 5 & 0.91 & 0.78 & 0.96 & 5.07 & 7.59 & 6.44 & 8.57 & 10.70 & 12.03 \\
\hline Group 6 & 0.89 & 0.75 & 0.98 & 5.15 & 7.51 & 6.48 & 8.41 & 10.76 & 12.19 \\
\hline Group 7 & 0.91 & 0.78 & 0.86 & 5.10 & 7.25 & 6.59 & 8.87 & 10.96 & 12.12 \\
\hline Group 8 & 1.06 & 0.81 & 0.89 & 4.82 & 7.45 & 6.45 & 9.49 & 11.18 & 12.42 \\
\hline Group 9 & 1.09 & 0.86 & 0.96 & 4.61 & 8.47 & 7.14 & 9.14 & 9.65 & 11.04 \\
\hline Group 10 & 0.92 & 0.81 & 0.88 & 4.45 & 6.69 & 6.09 & 9.40 & 12.00 & 12.72 \\
\hline Group 11 & 0.90 & 0.83 & 0.99 & 4.74 & 7.48 & 6.42 & 9.03 & 10.85 & 12.58 \\
\hline Group 12 & 0.89 & 0.87 & 0.93 & 4.72 & 7.06 & 6.66 & 9.05 & 11.27 & 11.62 \\
\hline Average & $\mathbf{0 . 9 4}$ & $\mathbf{0 . 8 0}$ & $\mathbf{0 . 9 5}$ & $\mathbf{5 . 0 4}$ & $\mathbf{7 . 6 8}$ & $\mathbf{6 . 5 5}$ & $\mathbf{8 . 7 4}$ & $\mathbf{1 0 . 6 6}$ & $\mathbf{1 2 . 1 4}$ \\
\hline Deviation & $\mathbf{0 . 0 4}$ & $\mathbf{- 0 . 1 0}$ & $\mathbf{0 . 0 5}$ & $\mathbf{0 . 5 4}$ & $\mathbf{1 . 3 8}$ & $\mathbf{0 . 2 5}$ & $\mathbf{0 . 0 3}$ & $\mathbf{- 1 . 5 3}$ & $\mathbf{- 0 . 0 5}$ \\
\hline
\end{tabular}

Table 5: Realised interest rate $r$ and price of goods $1 p_{1}$ and $2 p_{2}$. B: baseline, C: credit expansion, L: lump-sum transfers.

\begin{tabular}{|c||c|c|c||c|c|c|}
\hline \multicolumn{1}{|c||}{} & \multicolumn{3}{c||}{$g_{i, 1}$} & \multicolumn{3}{c|}{$g_{i, 2}$} \\
& $\mathrm{~B}$ & $\mathrm{C}$ & $\mathrm{L}$ & $\mathrm{B}$ & $\mathrm{C}$ & $\mathrm{L}$ \\
\hline Group 1 & 9.55 & 9.37 & 10.96 & 6.19 & 6.48 & 5.67 \\
\hline Group 2 & 10.70 & 9.75 & 12.63 & 5.83 & 6.23 & 4.79 \\
\hline Group 3 & 9.55 & 8.86 & 11.31 & 6.39 & 6.80 & 5.58 \\
\hline Group 4 & 10.54 & 9.22 & 10.84 & 5.84 & 6.54 & 5.78 \\
\hline Group 5 & 10.40 & 9.19 & 10.57 & 5.96 & 6.65 & 5.99 \\
\hline Group 6 & 10.49 & 9.48 & 10.67 & 5.91 & 6.48 & 5.94 \\
\hline Group 7 & 10.15 & 9.88 & 11.01 & 6.04 & 6.31 & 5.65 \\
\hline Group 8 & 10.29 & 9.45 & 10.27 & 5.96 & 6.51 & 6.12 \\
\hline Group 9 & 10.95 & 8.97 & 10.19 & 5.68 & 6.79 & 6.16 \\
\hline Group 10 & 10.47 & 9.29 & 10.40 & 6.01 & 6.61 & 6.07 \\
\hline Group 11 & 10.92 & 9.34 & 11.07 & 5.68 & 6.54 & 5.66 \\
\hline Group 12 & 10.00 & 9.81 & 10.78 & 6.15 & 6.36 & 5.87 \\
\hline Average & $\mathbf{1 0 . 3 3}$ & $\mathbf{9 . 3 9}$ & $\mathbf{1 0 . 8 9}$ & $\mathbf{5 . 9 7}$ & $\mathbf{6 . 5 2}$ & $\mathbf{5 . 7 7}$ \\
\hline Deviation & $\mathbf{- 0 . 7 8}$ & $\mathbf{- 1 . 7 2}$ & $\mathbf{- 0 . 2 2}$ & $\mathbf{0 . 2 3}$ & $\mathbf{0 . 7 8}$ & $\mathbf{0 . 0 3}$ \\
\hline
\end{tabular}

Table 6: Realised production of goods $1 g_{i, 1}$ and $2 g_{i, 2}$. B: baseline, C: credit expansion, L: lump-sum transfers. 

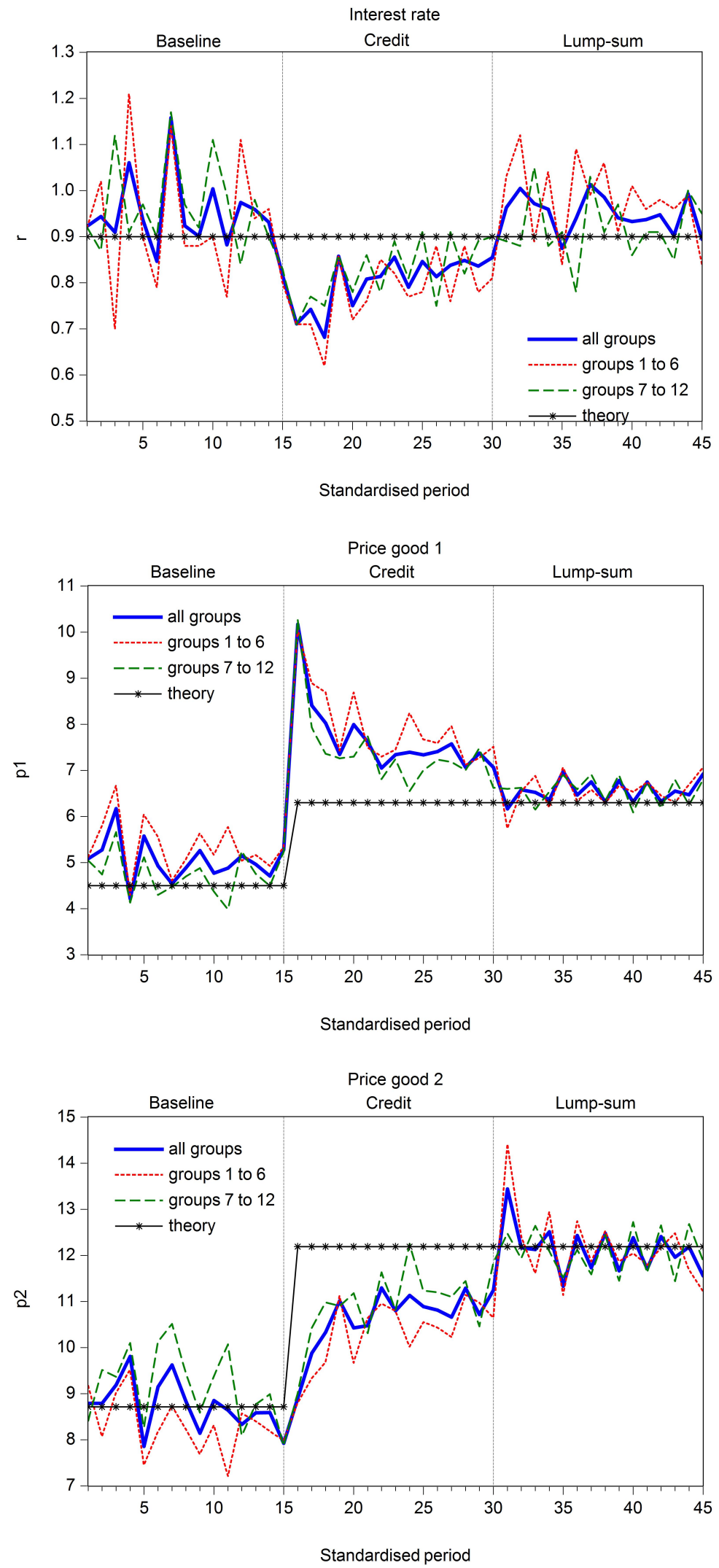

Figure 12: Average realised prices 


\section{B Convergence pattern}

\begin{tabular}{c|cccccc} 
& $\alpha=0.25$ & $\alpha=0.35$ & $\alpha=0.45$ & $\alpha=0.55$ & $\alpha=0.65$ & $\alpha=0.75$ \\
\hline$Z_{1}$ & 0.51 & 0.49 & 0.52 & 0.49 & 0.53 & 0.46 \\
& $(0.00)$ & $(0.00)$ & $(0.00)$ & $(0.00)$ & $(0.00)$ & $(0.00)$ \\
$Z_{2}$ & 0.32 & 0.40 & 0.47 & 0.50 & 0.61 & 0.70 \\
& $(0.00)$ & $(0.00)$ & $(0.00)$ & $(0.00)$ & $(0.00)$ & $(0.00)$ \\
$R^{2}$ & 0.31 & 0.12 & 0.05 & 0.00 & 0.07 & 0.44 \\
\hline
\end{tabular}

Table 7: Convergence pattern of decision 3. P-values in parentheses.

\begin{tabular}{l|ccc|ccc} 
& \multicolumn{3}{|c|}{$g_{i, 1}$} & \multicolumn{3}{c}{$g_{i, 2}$} \\
& $B$ & $C$ & $L$ & $B$ & $C$ & $L$ \\
\hline$Z_{1}$ & 10.56 & 7.33 & 11.87 & 5.76 & 7.49 & 5.21 \\
& $(0.00)$ & $(0.00)$ & $(0.00)$ & $(0.00)$ & $(0.00)$ & $(0.00)$ \\
$Z_{2}$ & 10.27 & 9.97 & 10.61 & 6.03 & 6.25 & 5.93 \\
& $(0.00)$ & $(0.00)$ & $(0.00)$ & $(0.00)$ & $(0.00)$ & $(0.00)$ \\
$R^{2}$ & 0.02 & 0.89 & 0.75 & 0.06 & 0.88 & 0.82 \\
\hline Equilibrium & 11.11 & 11.11 & 11.11 & 5.74 & 5.74 & 5.74 \\
\hline
\end{tabular}

Table 8: Convergence pattern of production of goods 1 and 2. P-values in parentheses.

\begin{tabular}{l|ccc|ccc|ccc} 
& \multicolumn{3}{|c|}{$r$} & \multicolumn{3}{|c|}{$p_{1}$} & \multicolumn{3}{c}{$p_{2}$} \\
& $B$ & $C$ & $L$ & $B$ & $C$ & $L$ & $B$ & $C$ & $L$ \\
\hline$Z_{1}$ & 0.94 & 0.68 & 0.98 & 5.31 & 10.07 & 6.24 & 9.06 & 8.86 & 13.24 \\
& $(0.00)$ & $(0.00)$ & $(0.00)$ & $(0.00)$ & $(0.00)$ & $(0.00)$ & $(0.00)$ & $(0.00)$ & $(0.00)$ \\
$Z_{2}$ & 0.95 & 0.84 & 0.94 & 4.97 & 6.99 & 6.64 & 8.65 & 11.17 & 11.83 \\
& $(0.00)$ & $(0.00)$ & $(0.00)$ & $(0.00)$ & $(0.00)$ & $(0.00)$ & $(0.00)$ & $(0.00)$ & $(0.00)$ \\
$R^{2}$ & 0.00 & 0.48 & 0.07 & 0.03 & 0.91 & 0.16 & 0.03 & 0.82 & 0.44 \\
\hline Equilibrium & 0.90 & 0.90 & 0.90 & 4.50 & 6.30 & 6.30 & 8.71 & 12.19 & 12.19 \\
\hline
\end{tabular}

Table 9: Convergence pattern of interest rate and good prices 1 and 2. P-values in parentheses. 


\section{Decisions across utility preference}
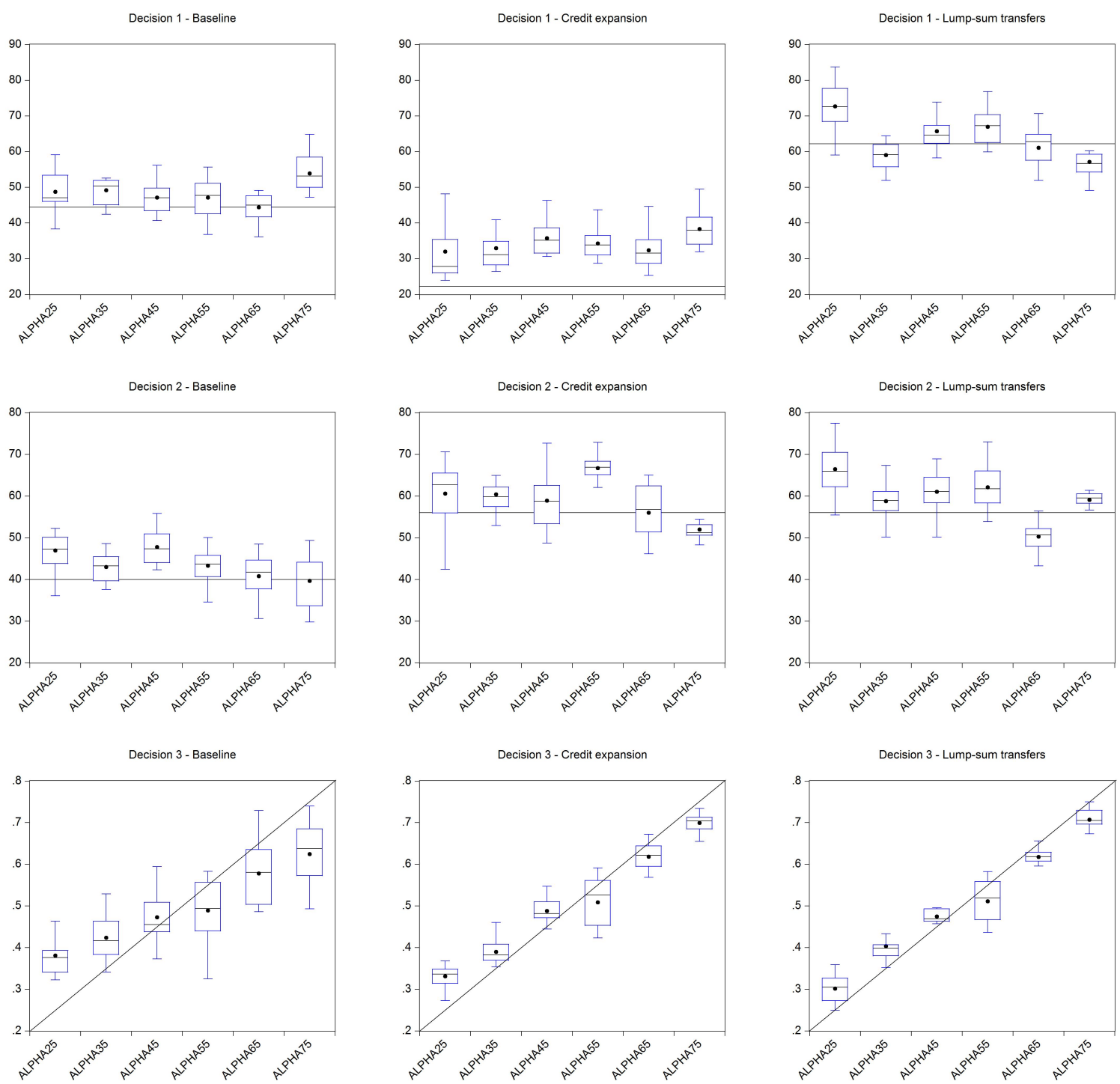

Figure 13: Distribution of decisions across utility preference $\alpha_{i}$ 


\section{Instructions}

Instructions to participants varied according to the treatments. We present the instructions for a treatment with order of stages: B, C, and L. For the other treatment (B, L, and $\mathrm{C}$ ), instructions were adapted accordingly and are available upon request. ${ }^{12}$

\section{Instructions}

\section{General information}

Thank you for participating in an experiment in which you can earn money. These earnings will be paid to you in cash at the end of the experiment.

We ask you not to communicate from now on. If you have a question, then raise your hand and the instructor will come to you.

You are a group of 18 persons in total participating in this experiment and you are allocated into three groups of 6 persons. These three groups are totally independent and do not interact one with another during the whole length of the experiment. Each participant interacts only with other participants in his group and not with the participants of the other groups.

The current instructions describe the rules of the game for a group of 6 participants.

The rules are the same for all the participants. The experiment consists of 3 stages, each including 15 periods. At each of the 45 periods, you are asked to make three decisions. Your payoff depends on the decisions you make all along the experiment. After each period, you are told about the outcome and your gains, which will allow you to adjust your decisions at each new period.

\section{General description of the experiment}

Each participant is an entrepreneur who produces and consumes two types of goods, good 1 and good 2. All transactions are made in ECU (Experimental Currency Unit) at market price. You have to decide how much to invest in the production of good 1 and good 2, and how much to consume of good 1 and good 2. Your production of good 1 and good 2 is sold at market price and it earns you an income that allows you to buy at market price your consumption of good 1 and good 2. The value of your consumption corresponds to the value of your production. However, the proportion of good 1 and good 2 that you consume does not necessarily correspond to the proportion of good 1 and good 2 that you produce. You have to optimise your production and your consumption in order to maximise your payoffs in ECUs.

At each period, you are endowed with an initial amount of ECUs. You have to make three decisions. The ECUs you are initially endowed with can either be invested in the production of good 1, or be lent on the credit market. There is no default risk on the credit market. The choice to invest in the production of good 1 and to lend on the credit market correspond to decision 1. The ECUs that you invest in the production of good 2 have to

\footnotetext{
${ }^{12}$ What follows is a translation (from French to English) of the instructions given to the participants.
} 
be borrowed on the credit market. The amount that you which to borrow and invest in the production of good 2 corresponds to decision 2. The amount in ECUs that you lend on the credit market (decision 1) does not necessarily correspond to the amount that you borrow for the production of good 2 (decision 2). Finally, you allocate the product of your production to the consumption of good 1 and good 2 . The allocation between goods 1 and 2 constitutes decision 3.

At each period, each participant makes his/her three decisions individually though at the same time of the other participants of his/her group. When all the participants of the same group have made their three decisions, you are told about the outcome of the period and the market prices.

Production (supply) and consumption (demand) of goods 1 and 2 determine prices of goods 1 and 2. The loans and borrowings on the credit market determine the interest rate. Prices as well as the market interest rate determine the payoff (in ECUs) that each participant gets owing to his/her production as well as the payoff associated with consumption of goods 1 and 2 .

The three decisions that you have to make at each of the 45 periods are now described more precisely.

\section{Decision 1: production of good 1, loan on the credit market}

To make decision 1, you have to split your initial ECUs into the amount that you choose to invest in the production of good 1 and the amount that you lend on the credit market. Concretely, you have to enter into the computer the amount of your initial ECUs that you want to lend on the credit market. The rest (of the initial amount of ECUs) corresponds to the amount that you invest in the production of good 1. For example, if you hold 100 initial ECUs and that you lend 30.0 ECUs on the credit market, your investment in the production of good 1 will be 70.0 .

The amount that you invest in the production of good 1 earns you the product of the sale of good 1 (quantity produced $\mathrm{x}$ price of good 1 ). The amount that you lend on the credit market earns you an interest (amount lent $\mathrm{x}$ interest rate).

You will neither know the price of good 1, nor the interest rate when you make your decision because they result from the decisions of all participants. However, from the second period on, you will know the price and the interest rate of the preceding period, which will allow you to adjust your decision at each new period.

During the first period, you have to make your decision with no information on price and interest rate. During the next periods, you have to maximise your payoffs by comparing the marginal product of the production of good 1 with the interest rate paid by the loan at the preceding period. If the interest rate that you earn owing to the loan is larger than the marginal product of the production of good 1, it will be profitable to increase (at the next period) the amount lent and thus to reduce your production of good 1. And conversely, if the interest rate is lower than the marginal product of good 1. For example, if the marginal product of the production of good 1 is 1.28 and the interest rate that you receive on your loan is 1.13 , it will be profitable to reduce your loan and to increase your 
production of good 1 at the next period.

\section{Decision 2: production of good 2, borrowing on the credit market}

To make decision 2, you have to decide the amount of ECUs that you want to borrow on the credit market to invest in the production of good 2. Concretely, you have to enter into the computer the amount that you want to borrow on the credit market.

The amount that you borrow and invest in the production of good 2 earn you the proceeds of the sale of good 2 (quantity produced x price of good 2) but costs you an interest (amount borrowed $\mathrm{x}$ interest rate).

You will neither know the price of good 2, nor the interest rate when you make your decision because they result from the decisions of all participants. However, from the second period on, you will know the price and the interest rate of the preceding period, which will allow you to adjust you decision at each period.

During the first period, you have to make your decision with no information on price and interest rate. During the next periods, you have to maximise your payoffs by comparing the marginal product of production of good 2 with the interest rate paid on borrowing. If the interest rate that you pay on your borrowing is larger than the marginal product of the production of good 2, it will be profitable to reduce your borrowing (at the next period) and thereby your production of good 2. And conversely if the interest rate is lower than the marginal product of good 2. For example, if the marginal product of production of good 2 is 1.24 and the interest rate paid on the borrowing is 1.13, it is profitable to increase your borrowing and your production of good 2 at the next period.

\section{Decision 3: consumption of good 1 and good 2}

To make decision 3 , you have to decide how to allocate your revenue between consumption of good 1 and good 2 in percentage. Consumption of goods 1 and 2 earns a payoff. Concretely, you have to enter into the computer the share between 0.01 and 0.99 of the revenue you would like to allocate to consumption of good 1 . The residual share of your revenue, which is 1 minus the value entered, is allocated to consumption of good 2 .

Your revenue comes from the production of good 1 and good 2 and from the interest received from your loan minus the interest paid on your borrowing. Your consumption of good 1 and good 2 does not necessarily correspond to your production of good 1 and good 2.

You have to share your consumption between good 1 and good 2 in order to maximise your payoff associated with the consumption of each good. To this aim, you have to compare the relative price of good 2 and good 1 with the marginal relative gain associated with consumption of good 2 and good 1.

You will neither know the relative price of good 2 and good 1 nor the marginal relative gain when you make your decision because they result from the decisions of all participants. However, from the second period on, you will know the relative price and the marginal gain of the preceding period, which will allow you to adjust your decision at each new period. 
If the relative price between good 2 and good 1 is larger than the marginal relative gain of consumption of good 2 compared to good 1, it will be profitable to reduce (at the next period) consumption of good 2 and increase consumption of good 1. And conversely, if the relative price between good 2 and good 1 is smaller than the marginal relative gain of good 2 compared to good 1. For example, if good 2 has the same price as good 1 (the relative price between good 2 and good $1=1$ ), but good 2 earns you a marginal gain that is twice that of good 1 (marginal relative gain of good 2 compared to that of good $1=2$ ), it is profitable to reduce your consumption of good 1 and to increase your consumption of good 2 at the next period.

\section{Running of the experiment}

For each of your decisions, once you made your decision, click on the input button. Once you made your 3 decisions, click on Validate to validate your decisions. Once all the participants validate their decisions, the outcome of the period appears on the screen. You will also know the gain associated to decisions 1 and 2, the gain associated to decision 3 , the marginal product of good 1 , the interest rate realised on the market, the marginal product of production of good 2, the relative price of good 2 compared to good 1 , the marginal relative gain of consumption of good 2 compared to good 1, and the total gain per period and cumulated on all the preceding periods.

\section{Steps: initial ECUs and credits}

The 45 periods of the experiment are divided in 3 steps, each composed of 15 periods. These 3 steps differ by the amount of ECUs you are initially endowed with and by the amount of ECUs offered on the credit market on top of loans granted by all participants.

During the first step (periods 1 to 15), the initial amount of ECUs each participant is endowed with at each period is 100 ECUs. The total amount of ECUs for each group is thus 600 ECUs at each period (6 participants x 100 ECUs). So you can make your lending decision 1 and your borrowing decision 2 between 0.1 and 99.9 .

During the second stage (periods 16 to 30), the initial amount of ECUs each participant is endowed with at each period is 100 ECUs. Moreover, 240 additional ECUs are offered on the credit market. The total amount of ECUs per group is thus 840 ECUs at each period (6 participants x 100 ECUs +240 ECUs offered on the credit market). Hence, you can make your lending decision 1 between 0.1 and 99.9 and your borrowing decision 2 between 0.1 and 139.9 .

During the third stage (periods 31 to 45), the initial amount of ECUs of each participant at each period is 140 ECUs. The total amount of ECUs per group is thus 840 ECUs at each period (6 participants x 140 ECUs). Hence, you can make your lending decision 1 and your borrowing decision 2 between 0.1 and 139.9 .

\section{Questionnaires}

At the beginning of the experiment, you are asked to fill in an understanding questionnaire on the computer; when all the participants have responded properly to this 
questionnaire, the experiment starts. At the end of the experiment, you are asked to fill in a personal questionnaire on the computer. All information will remain secret.

\section{Payoffs}

At the end of the experiment, the ECUs you have obtained are converted into Euros and paid in cash. 350 ECUs correspond to 1 Euro.

If you have any question, please ask them at this time.

\section{Thanks for participating in the experiment!}

\section{E Training questionnaire}

The training questionnaire varied according to the treatment. ${ }^{13}$ We present the questionnaire for a treatment with order of stages: B, C, and L. For the other treatment (B, L, and $\mathrm{C})$, the training questionnaire was adapted accordingly and is available upon request. ${ }^{14}$

Question 1: You interact with other participants at each period.

Answer: You interact with 5 other participants at each period..

Question 2: At each of the periods of the experiment, you have to make decisions.

Answer: At each of the 45 periods of the experiment, you have to make 3 decisions.

Question 3: The running of steps is the following. You have to make a lending decision between and ECUs and a borrowing decision between and ECUs at step 1, a lending decision between and ECUs and a borrowing decision between and ECUs at step 2, a lending decision between and ECUs and a borrowing decision between and ECUs at step 3.

Answer: You have to make a lending decision between 0.1 and 99.9 ECUs and a borrowing decision between 0.1 and 99.9 ECUs at step 1, a lending decision between 0.1 and 99.9 ECUs and a borrowing decision between 0.1 and 139.9 ECUs at step 2, a lending decision between 0.1 and 139.9 ECUs and a borrowing decision between 0.1 and 139.9 ECUs at step 3.

Question 4: To increase your production of good 1, what shall you do?

- Increase your loan in decision 1.

- Reduce your loan in decision 1.

- Reduce your borrowing in decision 2.

- Increase the share of your revenue that you allocate to consumption of good 1 in decision 3.

\footnotetext{
${ }^{13}$ Question 3 had to be adapted to the treatment.

${ }^{14}$ What follows is a translation (from French to English) of the training questionnaire participants had to fill in on their computer.
} 
Answer: Reduce your loan in decision 1.

Question 5: Imagine you are in period 6 of the experiment. At period 5, the interest rate was 3.00 and the marginal product of production of good 1 was 1.02 . Compared to period 5 , you now choose to:

- increase the amount that you lend (and thus reduce your production of good 1).

- reduce the amount that you lend (and thus increase your production of good $1)$.

Answer: increase the amount that you lend (and thus reduce your production of $\operatorname{good} 1)$.

Question 6: Imagine you are in period 24 of the experiment. At period 23, the interest rate was 4.25 and the marginal product of production of good 2 was 6.78. Compared to period 23, you now choose to:

- increase your borrowing (and thus your production of good 2).

- reduce your borrowing (and thus your production of good 2).

Answer: increase your borrowing (and thus your production of good 2).

Question 7: Imagine you are in period 40 of the experiment. At period 39, the relative price between good 2 and good 1 was 5.89 and the relative marginal gain of good 2 compared to good 1 was 4.76. Compared to period 39, you choose to:

- increase your consumption of good 1 and reduce your consumption of good 2 .

- increase your consumption of good 2 and reduce your consumption of good 1.

Answer: increase your consumption of good 1 and reduce your consumption of good 2 .

Question 8: What information is at your disposal to make your decisions at period 1 ?

- You will make your decisions in period 1 as in all other periods, by comparing the interest rate with the marginal product of production of good 1 for decision 1 , by comparing the interest rate with the marginal product of production of good 2 for decision 2, and by comparing the relative price between good 2 and good 1 and the relative marginal gain of consumption of good 2 compared to good 1 for decision 3 .

- You will not have any information available in period 1 (solely). The outcome of period 1 will allow you to improve your decisions in period 2, and so on.

Answer: You will not have any information available in period 1 (solely). The outcome of period 1 will allow you to improve your decisions in period 2, and so on. 


\section{F Example of screen}

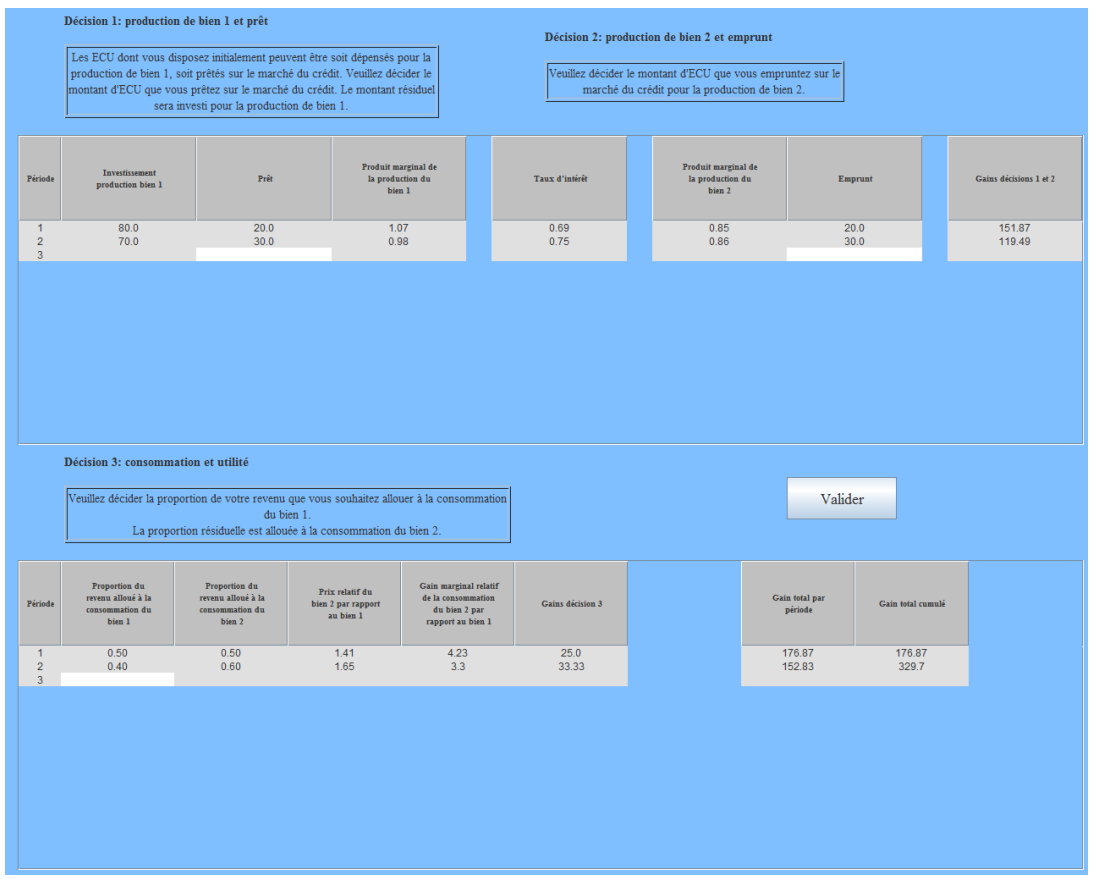

Figure 14: Screen 